\title{
A Secreted NIpC/P60 Endopeptidase from Photobacterium damselae subsp. piscicida Cleaves the Peptidoglycan of Potentially Competing Bacteria
}

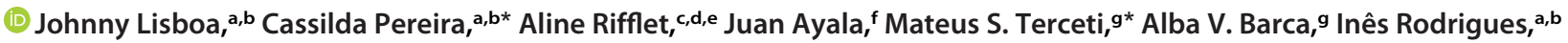 \\ (D) Pedro José Barbosa Pereira, h,i (1) Carlos R. Osorio,g (1) Francisco García-del Portillo,j Ivo Gomperts Boneca, ${ }^{\mathrm{c}, \mathrm{d}, \mathrm{e}}$ Ana do Vale, \\ Nuno M. S. dos Santos ${ }^{a, b}$
}

aFish Immunology and Vaccinology Group, Instituto de Biologia Molecular e Celular (IBMC), Universidade do Porto, Porto, Portugal

bFish Immunology and Vaccinology Group, Instituto de Investigação e Inovação em Saúde (i3S), Universidade do Porto, Porto, Portugal

cInstitut Pasteur, Unité Biologie et Génétique de la Paroi Bactérienne, Paris, France

dINSERM Groupe Avenir, Paris, France

eCNRS, UMR "Integrated and Molecular Microbiology," Paris, France

fCentro de Biología Molecular Severo Ochoa (CBMSO), Consejo Superior de Investigaciones Científicas (CSIC), Madrid, Spain

gDepartamento de Microbioloxía e Parasitoloxía, Instituto de Acuicultura, Universidade de Santiago de Compostela, Santiago de Compostela, Spain

hBiomolecular Structure Group, Instituto de Biologia Molecular e Celular (IBMC), Universidade do Porto, Porto, Portugal

'Macromolecular Structure Group, Instituto de Investigação e Inovação em Saúde (i3S), Universidade do Porto, Porto, Portugal

jLaboratorio de Patógenos Bacterianos Intracelulares, Centro Nacional de Biotecnología (CNB), Consejo Superior de Investigaciones Científicas (CSIC), Madrid, Spain

ABSTRACT Peptidoglycan (PG) is a major component of the bacterial cell wall, forming a mesh-like structure enwrapping the bacteria that is essential for maintaining structural integrity and providing support for anchoring other components of the cell envelope. PG biogenesis is highly dynamic and requires multiple enzymes, including several hydrolases that cleave glycosidic or amide bonds in the PG. This work describes the structural and functional characterization of an NIpC/P60-containing peptidase from Photobacterium damselae subsp. piscicida (Phdp), a Gram-negative bacterium that causes high mortality of warm-water marine fish with great impact

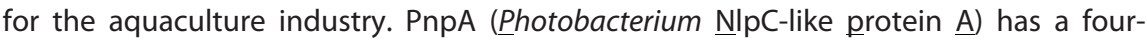
domain structure with a hydrophobic and narrow access to the catalytic center and specificity for the $\gamma$-D-glutamyl-meso-diaminopimelic acid bond. However, PnpA does not cleave the PG of Phdp or PG of several Gram-negative and Gram-positive bacterial species. Interestingly, it is secreted by the Phdp type II secretion system and degrades the PG of Vibrio anguillarum and Vibrio vulnificus. This suggests that PnpA is used by Phdp to gain an advantage over bacteria that compete for the same resources or to obtain nutrients in nutrient-scarce environments. Comparison of the muropeptide composition of PG susceptible and resistant to the catalytic activity of PnpA showed that the global content of muropeptides is similar, suggesting that susceptibility to PnpA is determined by the three-dimensional organization of the muropeptides in the PG.

IMPORTANCE Peptidoglycan (PG) is a major component of the bacterial cell wall formed by long chains of two alternating sugars interconnected by short peptides, generating a mesh-like structure that enwraps the bacterial cell. Although PG provides structural integrity and support for anchoring other components of the cell envelope, it is constantly being remodeled through the action of specific enzymes that cleave or join its components. Here, it is shown that Photobacterium damselae subsp. piscicida, a bacterium that causes high mortality in warm-water marine fish, produces PnpA, an enzyme that is secreted into the environment and is able to cleave the PG of potentially competing bacteria, either to gain a competitive advantage and/or to

Citation Lisboa J, Pereira C, Rifflet A, Ayala J, Terceti MS, Barca AV, Rodrigues I, Pereira PJB, Osorio CR, García-del Portillo F, Gomperts Boneca I, do Vale A, dos Santos NMS. 2021. A secreted NIpC/P60 endopeptidase from Photobacterium damselae subsp. piscicida cleaves the peptidoglycan of potentially competing bacteria. mSphere 6:e0736-20 https://doi.org/10.1128/mSphere.00736-20 Editor Ana Cristina Gales, Escola Paulista de Medicina/Universidade Federal de São Paulo Copyright $\odot 2021$ Lisboa et al. This is an openaccess article distributed under the terms of the Creative Commons Attribution 4.0 International license.

Address correspondence to Johnny Lisboa, johnny.lisboa@ibmc.up.pt, or Nuno M. S. dos Santos, nsantos@ibmc.up.pt.

* Present address: Cassilda Pereira, Stem Cells in Regenerative Biology and Repair, Instituto Nacional de Engenharia Biomédica (INEB), Universidade do Porto, Porto, Portugal, and Instituto de Investigação e Inovação em Saúde (i3S), Universidade do Porto, Porto, Portugal; Mateus S. Terceti, Departamento de Biologia Geral e Aplicada, Instituto de Biociências de Rio Claro-São Paulo, Universidade Estadual Paulista (ENESP), São Paulo, Brazil.

Received 18 July 2020

Accepted 8 January 2021

Published 3 February 2021 
obtain nutrients. The specificity of PnpA for the PG of some bacteria and its inability to cleave others may be explained by differences in the structure of the PG mesh and not by different muropeptide composition.

KEYWORDS NIpC/P60, Vibrio anguillarum, Vibrio vulnificus, X-ray crystallography, cell wall hydrolases, peptidoglycan, Photobacterium damselae subsp. piscicida, type II secretion system

eptidoglycan (PG) is a major component of the bacterial cell wall, essential for maintaining structural integrity and internal osmotic pressure, shaping the morphology of bacteria, and providing support for anchoring other components of the cell envelope $(1,2)$. PG forms a mesh-like structure that enwraps the bacterial cell, referred to as sacculus, which is composed of long chains of two alternating $\beta(1-4)$ glycosidicbonded glycans, $\mathrm{N}$-acetylglucosamine (GlcNAc) and $\mathrm{N}$-acetylmuramic acid (MurNAc), crosslinked by short stem peptides, either directly or through bridging peptides (1, 3-5). The stem peptides are usually 4 or 5 amino acids long, contain L- and D-amino acids, and extend from MurNAc (1-4). The most common structure of the stem peptide is L-Ala- $\gamma-D-$ Glu-mDAP-D-Ala-D-Ala (mDAP stands for meso-diaminopimelic acid) in Gram-negative bacteria and L-Ala- $\gamma$-D-Glu-L-Lys-D-Ala-D-Ala in Gram-positive organisms (1, 2, 4).

In spite of its stabilizing function, PG is highly dynamic, with covalent bonds being formed and broken by different enzymes. Multiple hydrolases, capable of cleaving glycosidic (glycosidases) or amide (amidases and peptidases) bonds in the PG sacculus and/or its soluble fragments, play a preponderant role in $P G$ dynamics (1, 2, 6-13). Degradation products resulting from the catalytic activity of PG hydrolases can be recycled for PG de novo biosynthesis and also act as signaling molecules in quorum sensing, triggering antibiotic resistance or regrowth of dormant cells or as effector molecules in immune responses $(1,2,6,7,12,14,15)$. Besides their role in PG dynamics, hydrolases can also be secreted to the environment or injected via type VI secretion systems into the periplasm of other bacteria to confer competitive advantage over competing bacteria that share mixed growth environments or as a way of obtaining nutrients $(1,10,11,16-23)$.

PG peptidases are a widely diverse group of enzymes, with 10 different types of catalytic domains involved in PG hydrolysis described thus far $(1,24)$. Of these enzymes, cysteine peptidases containing new lipoprotein $\underline{\mathrm{C}} /$ protein of $60-\mathrm{kDa}$ (NIpC/P60) catalytic domains are present in most bacterial lineages, suggesting that they play an important biological role $(1,24)$. NIpC/P60-containing peptidases are involved in the catalysis of the $\mathrm{N}$-acetylmuramate-L-alanine or $\mathrm{D}-\gamma$-glutamyl-meso-diaminopimelate linkages, with four major groups identified so far: (i) P60-like, (ii) AcmB/LytN-like, (iii) YaeF/poxvirus G6R, and (iv) lecithin retinol acyltransferase (LRAT)-like (24). The $\mathrm{NIpC/P60} \mathrm{domain} \mathrm{is} \mathrm{structurally} \mathrm{similar} \mathrm{to} \mathrm{a} \mathrm{primitive} \mathrm{papain-like} \mathrm{peptidase} \mathrm{(24-29)}$ and can be found alone or fused to other domains, with or without catalytic functions, to form multifunctional proteins $(1,2,24,26,30-35)$. Several of these domains, such as the SH3 (sarcoma homology 3 ) domain $(31,32,35)$, are involved in anchoring hydrolases to cell wall components, allowing their appropriate concentration and positioning for the formation of an efficient enzyme-substrate complex (1).

Photobacterium damselae subsp. piscicida (Phdp) is a Gram-negative, halophilic bacterium that induces an acute infection that rapidly develops into septicemia, resulting in high mortality of warm-water marine fish with devastating consequences for the aquaculture industry $(36,37)$. Although it has been suggested that Phdp remains in a cultivable form in salt water for only 4 or 5 days $(38,39)$, it was also suggested that it has the ability to enter a dormant, noncultivable but infectious state in salt water and sediment (40). With regard to the mechanisms responsible for the pathogenicity of Phdp, it was shown that extracellular products (ECPs) play a fundamental role $(41,42)$ although among their components, only the toxin AIP56 has been identified and characterized so far (43-47). 
The present work reports the structural and functional characterization of a novel NlpC/P60-containing peptidase from Phdp (PnpA). The results show that PnpA is a PG hydrolase with a four-domain structure similar to that of Desulfovibrio vulgaris lysin (DvLysin) and specificity for the $\gamma$-D-glutamyl-meso-diaminopimelic acid bond (26), but with a more hydrophobic and narrower access to the catalytic center. It is also shown that PnpA is secreted into the extracellular medium by the Phdp type II secretion system and acts on the PG of Vibrio anguillarum and Vibrio vulnificus, suggesting that it may provide Phdp an advantage over bacteria competing for the same resources or a way of obtaining nutrients in nutrient-scarce environments, either inside or outside the host. Comparison of the muropeptide compositions of PG, susceptible and resistant to PnpA activity, allowed development of a model suggesting that the susceptibility to PnpA is determined by three-dimensional structural features of the PG and not by their chemical compositions.

\section{RESULTS}

Photobacterium damselae subsp. piscicida secretes an NIpC/P60 family protein. Photobacterium damselae subsp. piscicida (Phdp) virulent strains have a relatively simple profile of secreted proteins in mid-exponential-growth-phase cultures (45). Apart from AIP56 toxin, no other proteins have been identified and characterized. Sodium dodecyl sulfate-polyacrylamide gel electrophoresis (SDS-PAGE) analysis of proteins from Phdp extracellular products (ECPs) precipitated with trichloroacetic acid (TCA) revealed a band of approximately $55 \mathrm{kDa}$ that was excised from the gel and subjected to matrix-assisted laser desorption ionization-time of flight mass spectrometry (MALDI-TOF MS). The obtained MS data were used in a Mascot search against the NCBI database resulting in the identification of a hypothetical protein from Photobacterium damselae subsp. damselae (Phdd) CIP 102761 (VDA_000779; NCBI accession number EEZ39759). The 1,479-nucleotide homologous sequence in the Phdp MT1415 strain (accession number TJZ86030.1) was then amplified using primers designed based on the VDA_000779 sequence. In silico analysis (SignalP 5.0 and NCBI conserved domain search) of its 499-amino-acid translation product predicted a Sec signal peptide $\left(\mathrm{M}^{1}\right.$ to $A^{19}$ ), followed by an N_NLPC_P60 putative stabilizing domain (Pfam PF12912), an SH3b1 (Pfam PF12913/12914), and an NlpC_P60 domain (Pfam PF00877), classifying it as a protein belonging to the NIpC/P60 family, hereafter referred to as PnpA (Photobacterium NIpC-like protein $\underline{A}$ ).

PnpA is encoded in a genetically unstable chromosomal region, and its expression levels are similar at exponential and stationary phases of growth. To investigate the genetic context of pnpA in Phdp MT1415 strain, the draft genome sequence of MT1415 was obtained in this study. Then, homologous DNA sequences of a number of Phdp and Phdd isolates were additionally retrieved from the GenBank database and subjected to comparative sequence analysis (Fig. 1). This revealed that the PnpA-encoding gene is invariably linked to a downstream gene encoding an RNase $\mathrm{T}$ and to an upstream gene encoding an $\alpha$-galactosidase, the latter being a pseudogene in some Phdp isolates. As a whole, the DNA flanking pnpA underwent a massive insertion of transposase genes (IS elements of the IS1 and IS91 families) likely followed by accumulation of inactivating mutations, resulting in a collection of pseudogenes. This process of gene decay not only affected the transposase genes themselves but also flanking genes encoding enzymes putatively involved in sugar metabolism, as $\alpha$-galactosidases, $\alpha$-amylases, and pullulanases (Fig. 1). Proliferation of insertion sequences that cause a high frequency of pseudogenes and gene loss is indeed a hallmark of all Phdp genomes studied thus far (48-50). The observation that PnpA- and the RNase T-encoding genes have escaped the inactivation by IS insertions suggests that these two genes may fulfill an important role in Phdp.

Expression levels of $p n p A$ were determined by reverse transcription-PCR (RT-PCR), showing that under the culture conditions used (growth in tryptic soy broth supplemented with $\mathrm{NaCl}$ to a final concentration of $1 \%$ [wt/vol] [TSB-1] at $25^{\circ} \mathrm{C}$ ), there are no 


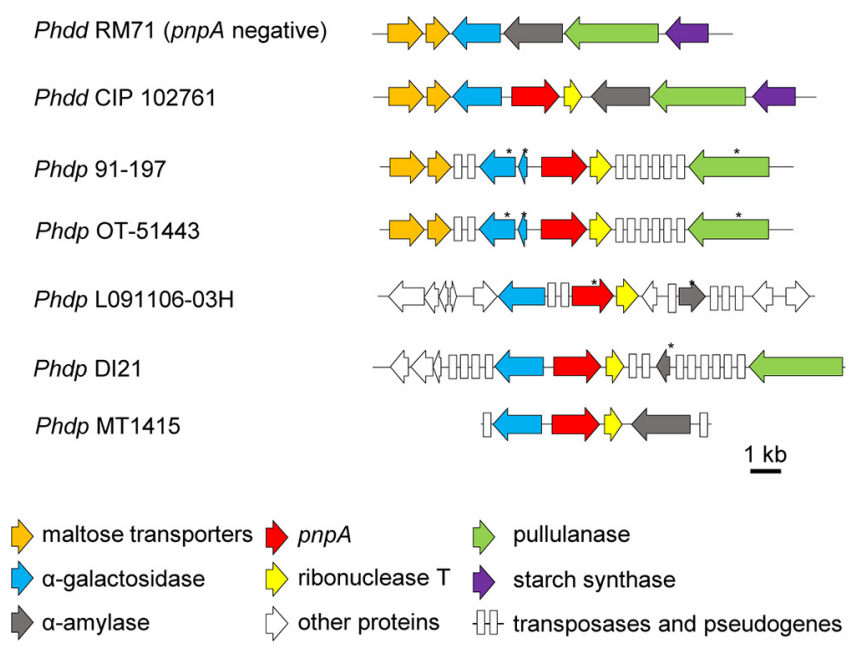

FIG 1 Genomic context of pnpA. Schematic representation of the genomic context of pnpA (shown in red) in the indicated Photobacterium damselae subsp. damselae (Phdd) and Photobacterium damselae subsp. piscicida (Phdp) strains. An asterisk denotes a truncated gene version.

differences in the level of gene transcription between exponential- and stationaryphase cultures (see Fig. S1 in the supplemental material).

Overall description of PnpA structure. For better understanding of the structurefunction relationship of PnpA, its three-dimensional structure was solved. The crystal structure of PnpA was determined at 1.4-Å resolution by molecular replacement with DvLysin (PDB entry 3M1U, 26\% sequence identity), an endopeptidase from Desulfovibrio vulgaris Hildenborough (26). The crystal asymmetric unit contains two PnpA molecules, which are essentially identical (root mean square deviation [RMSD], of $0.5 \AA$ for 457 aligned $\mathrm{C} \alpha$ atoms). Table $\mathrm{S} 1$ in the supplemental material summarizes the data collection, processing, and refinement statistics.

Analysis of the intermolecular packing interfaces within the crystal lattice suggests that the molecule behaves as a monomer in solution, which is in agreement with the molecular mass estimated by size exclusion chromatography. The PnpA monomer has an overall structure similar to that of DvLysin (26), namely, one N-terminal "c-clip" or "N_NLPC_P60" stabilizing domain (residues $\mathrm{N}^{20}-\mathrm{N}^{133}$ ), two SH3b domains (SH3b1, residues I134-V218; SH3b2, residues D219-T295), and the C-terminal NlpC/P60 catalytic domain (residues $\mathrm{P}^{296}-\mathrm{K}^{499}$ ) (Fig. 2A). The three-dimensional models of DvLysin and PnpA display an RMSD of $2.2 \AA$ (for 405 aligned $C \alpha$ atoms), suggesting that both proteins may be functionally equivalent. A significant number of structures sharing at least one of the PnpA domains have been identified (Table S2), although so far, PnpA and DvLysin are the only four-domain NlpC/P60-containing peptidases whose structure has been reported.

As in DvLysin (26), the PnpA c-clip domain has an extended helical conformation which surrounds and stabilizes the SH3b1 and NlpC/P60 domains, forming a planar assembly from which the SH3b2 domain protrudes (Fig. S2). Compared to DvLysin, the cclip domain of PnpA harbors an extension between helices $\alpha 1$ and $\alpha 2$, thereby forming an additional two-stranded antiparallel $\beta$-sheet ( $\beta 2$ and $\beta 3$ ) and a $3_{10}$ helix ( $\left.\eta 4\right)$, which protrude into the catalytic groove and close one of its sides (Fig. 2B).

The presence of $\mathrm{SH} 3 \mathrm{~b}$ domains in prokaryotes has long been documented. These domains have been described as targeting domains, involved in cell wall recognition and binding $(1,24,35)$. Despite the lack of amino acid sequence conservation $(8 \%$ sequence identity), the two SH3b domains in PnpA have a conserved overall fold (RMSD of $3.9 \AA$ for 55 aligned $C \alpha$ atoms) (Fig. S3). As in DvLysin (26), both PnpA SH3b domains consist of seven conserved strands ( $\beta \mathrm{A}-\beta \mathrm{A} 1-\beta \mathrm{A} 2-\beta \mathrm{B}-\beta \mathrm{C}-\beta \mathrm{D}-\beta \mathrm{E})$, with the $\beta \mathrm{A}-\beta \mathrm{E}$ strands structurally equivalent to their eukaryotic counterparts $(31,32)$, while 

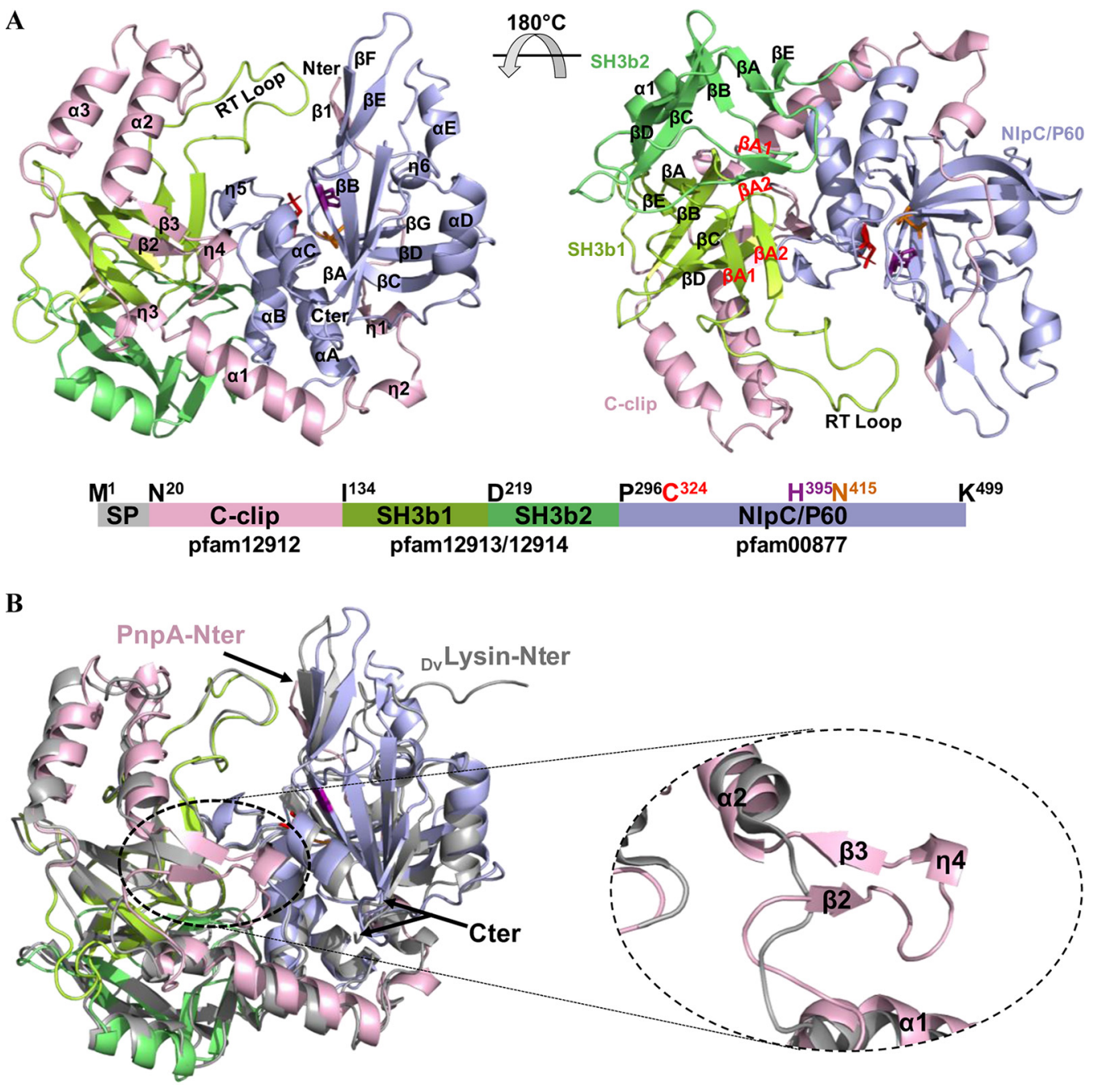

FIG 2 Three-dimensional structure of Phdp PnpA. (A) Cartoon representation of the PnpA monomer, with domains colored as in the linear representation shown below. The signal peptide (SP) (gray), C-clip domain (pink), SH3b1 domain (light green), SH3b2 domain (dark green), NlpC/P60 domain (purple), and domain boundaries and catalytic residues are indicated. The catalytic site residues are represented as sticks (C324 [red], H395 [magenta], and N415 [orange]). The $\mathrm{N}$ and $\mathrm{C}$ termini (Nter and Cter, respectively) and secondary structure elements are labeled. (B) Cartoon representation of superposed PnpA (color code as in panel A) and DvLysin (gray). N and C termini are indicated. A close-up of the insertion between $\alpha 1$ and $\alpha 2$, forming an additional antiparallel $\beta$-sheet $(\beta 2$ and $\beta 3)$ and a $3_{10}$ helix $(\eta 4)$ in the c-clip domain, is shown in the insert (dashed oval).

$\beta \mathrm{A} 1$ and $\beta \mathrm{A} 2$ form a $\beta$-hairpin that corresponds to the RT loops of eukaryotic $\mathrm{SH} 3 \mathrm{~b}$ domains (Fig. 2A).

As in other NlpC/P60-containing peptidases, the 204-residue-long C-terminal NIpC/ P60 catalytic domain of PnpA displays a fold resembling a primitive papain-like cysteine peptidase (24). Its secondary structure elements adopt the topology described for DvLysin, i.e., a six-stranded central $\beta$-sheet and five $\alpha$-helices with $\alpha \mathrm{A}-\alpha \mathrm{B}-\alpha \mathrm{C}-\beta \mathrm{A}-\alpha \mathrm{D}$ $\beta \mathrm{B}-\beta \mathrm{C}-\beta \mathrm{D}-\beta \mathrm{E}-\alpha \mathrm{E}-\beta \mathrm{F}$ topology, where $\alpha \mathrm{A}-\alpha \mathrm{B}-\alpha \mathrm{C}$ and $\alpha \mathrm{D}-\alpha \mathrm{E}$ protect either side of the central $\beta$-sheet (Fig. 2A) (26).

PnpA has a narrow and hydrophobic access to the catalytic site. The active site of NIpC/P60 cysteine peptidases consists of a conserved cysteine-histidine dyad and a third polar residue $(\mathrm{H}, \mathrm{N}$, or $\mathrm{Q})$ that orients and polarizes the catalytic histidine (24-29). In PnpA, the residues that make up the active site are C324, H395, and N415, the latter similar to the equivalent residue found in the active site of the prototypical papain (51), but differing from the histidine (H408) at the active site of DvLysin (26) (Fig. 3A). As described for other NIpC/P60-containing peptidases (24-29), the catalytic C324 is 


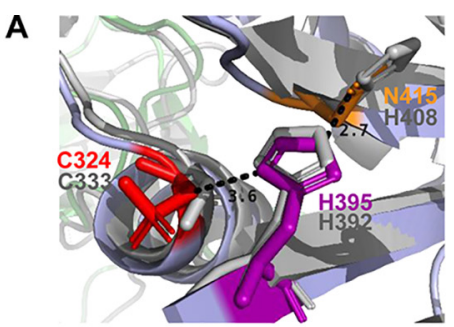

B
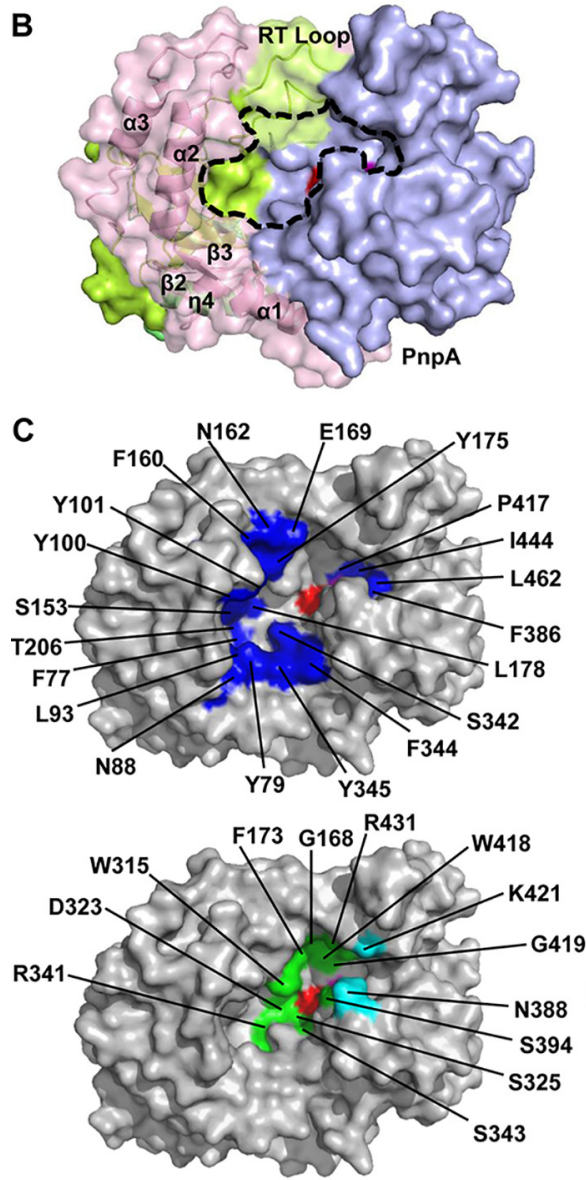
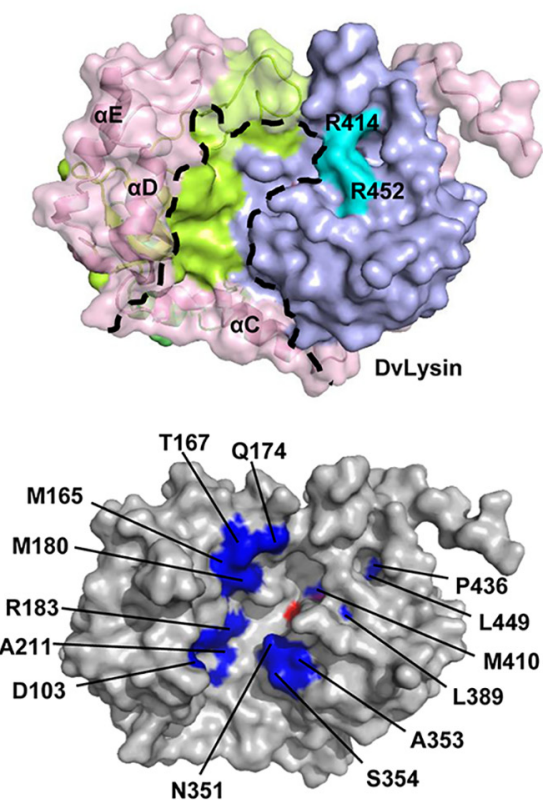

F178 G173 W411 R423

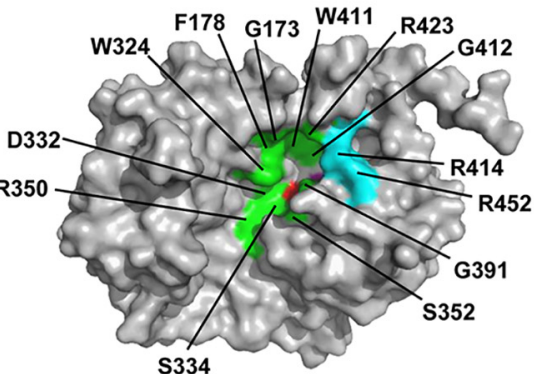

FIG 3 Structural comparison of the active sites of PnpA and DvLysin. (A) Superposition of the catalytic site of PnpA (colored sticks) and DvLysin (gray sticks). Dashed line indicates the distance between amino acid residues in angstroms. (B) Solid surface representation of PnpA (left) and DvLysin (right). Catalytic grooves are outlined by dashed lines. Residues R414 and R452 from DvLysin are colored cyan and labeled. (C) Comparison of the catalytic cavities of PnpA (left) and DvLysin (right). Hydrophobic and polar residues close to the substrate binding region are colored dark blue (top panel). DvLysin residues involved in substrate binding (27) and conserved in PnpA are colored green (bottom panel). Catalytic residues are colored as in Fig. 2A.

located at the amino terminus of a helix packing against the central $\beta$-sheet that harbors $\mathrm{H} 395$ in its second strand and N415 in the third. In the PnpA structure, the thiol group of the catalytic cysteine is oxidized, resulting in the disruption of the characteristic C324 SD-H395 ND1 hydrogen bond and suggesting that the enzyme is in an inactive state (Fig. S4). As advanced for Bacteroides thetaiotamicron YkfC (BtYkfC) (26), oxidation of the catalytic cysteine most likely occurred during crystallization or exposure to X-rays (52), since recombinant PnpA from the same purification batch was used in biochemical assays and was catalytically active.

In DvLysin, access to the catalytic cysteine occurs through a groove between the $\mathrm{NIpC/P60} \mathrm{domain} \mathrm{on} \mathrm{one} \mathrm{side} \mathrm{and} \mathrm{the} \mathrm{c-clip} \mathrm{helices} \alpha \mathrm{D}$ and $\alpha \mathrm{E}$ plus the SH3b1 domain 
A

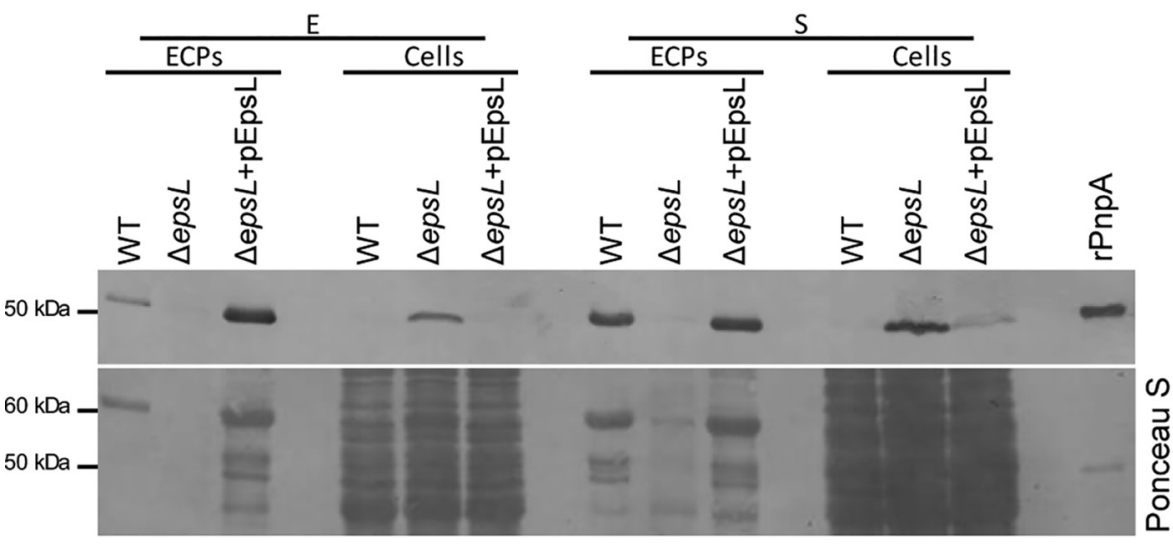

B

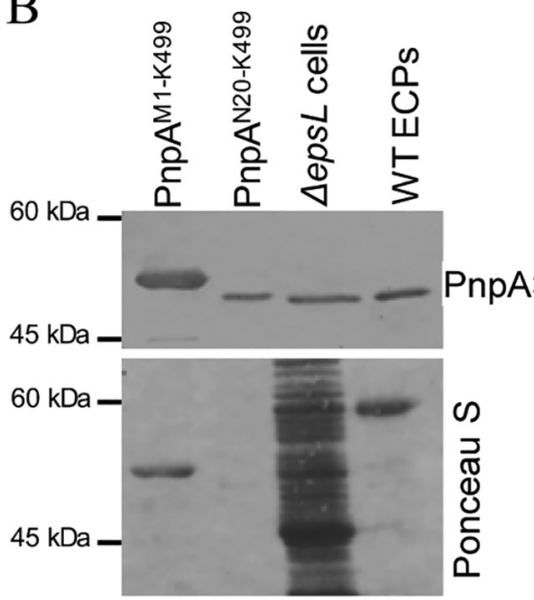

FIG 4 Secretion of PnpA is dependent on the type II secretion system (T2SS). (A) Wild type, $\Delta$ epsL, and $\Delta$ epsL complemented ( $\Delta$ eps + pEpsL) strains grown to an $\mathrm{OD}_{600}$ of 0.5 (exponential phase [E]) or 1.5 (stationary phase [S]). Extracellular products (ECPs) and bacterial pellets (Cells) were subjected to SDS-PAGE, and PnpA was detected by Western blotting (top panel). Recombinant PnpA (rPnpA; $0.2 \mu \mathrm{g}$ ) was used as a positive control. The bottom panel shows total protein loading (Ponceau S). The blot shown is representative of three independent experiments. (B) In $\Delta$ eps $L$ cells, PnpA is retained at the periplasm. Western blotting of PnpA retained in $\Delta$ eps $L$ cells and secreted by the WT bacteria (top panel). rPnpA containing and lacking the Sec signal peptide ( $\mathrm{PnpA}^{\mathrm{M} 1-\mathrm{K} 499}$ and $\mathrm{PnpA}^{\mathrm{N} 20-\mathrm{K} 499}$, respectively) were run as references. Please note that PnpA retained in $\Delta e p s L$ cells migrates similarly to the PnpA secreted by the WT bacteria, confirming the removal of the signal peptide and, thus, the periplasmic localization of PnpA in $\Delta e p s L$ cells. The bottom panel shows total protein loading (Ponceau S).

on the other, with the RT loop from the $\mathrm{SH} 3 \mathrm{~b} 1$ domain closing one end of the groove (Fig. 3B) (26). While this topology is generally maintained in PnpA, the end of the groove opposite to the RT loop is also closed by strands $\beta 2$ and $\beta 3$ and the $3_{10}$ helix $\eta 4$, creating a narrower access to the catalytic site (Fig. 3B). A minor difference is observed on the "wall" formed by the NIpC/P60 domain, wider in PnpA and closed by R414 and R452 in DvLysin (Fig. 3B). Besides the narrower entrance, two clusters of amino acids confer to the active site cavity of PnpA a more polar and hydrophobic nature than observed for DvLysin (Fig. 3C). However, extensive conservation of substrateinteracting residues between PnpA and DvLysin (Fig. 3C) suggests a similar interaction with meso-diaminopimelic acid (mDAP)-D-Ala from the stem peptide.

PnpA is secreted by Phdp type II secretion system. PnpA possesses a typical Sec signal peptide and was identified in the culture supernatants of exponentially growing Phdp cultures, suggesting that it could be actively secreted by the bacteria. Many proteins that are transported via the Sec system into the periplasm are secreted across the outer membrane through a type II secretion system (T2SS) $(53,54)$. Recently, it was shown that Phdp contains a functional T2SS (44) and that deletion of epsL, which encodes an inner membrane-spanning protein that establishes a critical link between the cytoplasmic and periplasmic parts of that system (55), abolishes the secretion of AIP56 (44). To test the involvement of the T2SS of Phdp in PnpA secretion, the presence of PnpA in total cell lysates and extracellular products of wild-type (WT), $\Delta e p s L$, and $\Delta$ epsL + pEpsL Phdp was analyzed by Western blotting (Fig. 4). PnpA was detected in ECPs, but not in total cell lysates of the WT strain, confirming that it is a secreted protein (Fig. 4A). In contrast, in the $\Delta$ epsL strain, PnpA was retained in the cell, likely in the periplasm (Fig. 4B), confirming the involvement of T2SS in PnpA secretion.

PnpA has specificity for the $\gamma$-D-glutamyl-meso-diaminopimelic acid bond. To investigate the PnpA enzymatic activity toward PG muropeptides and define its substrate specificity, recombinant PnpA was incubated with monomeric trimuropeptides (M3; GlcNAcMurNAc-L-Ala-D-Glu-mDap), tetramuropeptides (M4; GlcNAc-MurNAc-L-AlaD-Glu-mDap-D-Ala), and pentamuropeptides (M5; GlcNAc-MurNAc-L-Ala-D-Glu-mDap-DAla-D-Ala) and the cleavage product(s) analyzed by high-performance liquid chromatography (HPLC) (Fig. 5). PnpA converted all tested muropeptides to dipeptides (M2; GlcNAc-MurNAc-L-Ala-D-Glu), suggesting it cleaves specifically $\gamma$-D-glutamyl-meso-diaminopimelic acid bond of monomeric muropeptides. 

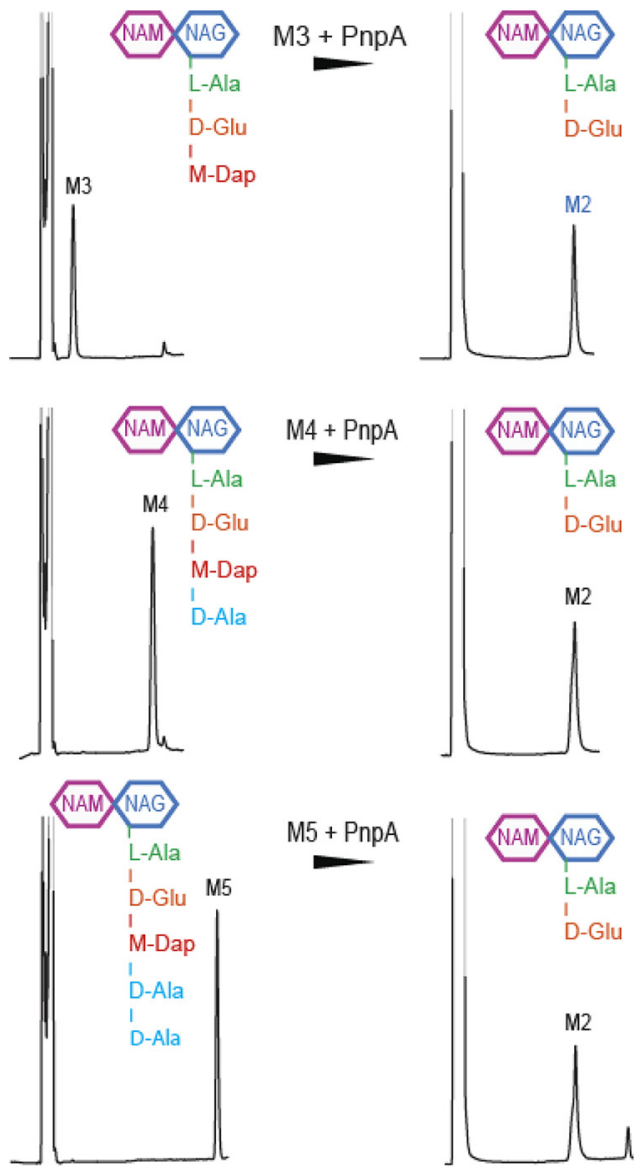

FIG 5 PnpA cleaves monomeric muropeptides M3, M4, and M5. HPLC profiles of each muropeptide at time zero (left) and after $3 \mathrm{~h}$ of incubation (right) with $50 \mu \mathrm{g} \mathrm{ml}{ }^{-1}$ recombinant PnpA (rPnpA). Note that after incubation with PnpA, M2 was always obtained as a product. M3, GlcNAc-MurNAc-LAla-D-Glu-mDAP-D-Ala-d-Ala; M4, GlcNAc-MurNAc-L-Ala-D-Glu-mDAP-D-Ala; M5, GlcNAc-MurNAc-L-Ala-DGlu-mDAP-D-Ala-D-Ala.

PnpA does not hydrolyze Phdp peptidoglycan. In order to evaluate the involvement of PnpA in Phdp cell wall biogenesis, a Phdp $\Delta p n p A$ strain was generated, and the absence of PnpA expression in the mutant strain was confirmed by SDS-PAGE and Western blotting (Fig. $6 \mathrm{~A}$ and B). Bacterial growth was not affected in the $\triangle p n p A$ strain (Fig. 6C). In addition, no differences were detected in the composition of the peptidoglycan from the WT and $\Delta p n p A$ strains (Fig. 6D; Table 1). In agreement with this, both WT and $\triangle p n p A$ strains showed similar morphology (Fig. 6E). Moreover, PnpA did not display in vitro enzymatic activity against $P h d p$ whole sacculus, since no differences in the muropeptide composition were detected after incubating the PG with active PnpA or inactive PnpA (Fig. 6F and Fig. S5A; Table 2). Altogether, these results suggest that PnpA is not enzymatically active toward intact Phdp PG.

PnpA has hydrolytic activity toward Vibrio anguillarum and Vibrio vulnificus PG. The facts that PnpA is actively secreted into the extracellular medium and has no enzymatic activity for Phdp PG raised the possibility that it could cleave PG from other bacteria, functioning as a weapon against competing bacteria or as part of a mechanism to acquire nutrients, e.g., muropeptides from dead bacteria. To address this issue, whole sacculi from several Gram-positive or Gram-negative bacteria were isolated and incubated in vitro with recombinant PnpA or catalytically inactive PnpA (PnpA ${ }^{\text {C324A }) ~}$ (Fig. 7 and Fig. S5B to J). Interestingly, only sacculi from $V$. anguillarum and V. vulnificus were sensitive to the action of PnpA (Fig. 7 and Fig. S5B and C and S6). Analysis of the insoluble sacculi resulting from digestion with $\mathrm{PnpA}$ showed the appearance of novel 
A $\frac{\text { ECPs }}{\frac{1}{2}} \frac{\text { Cells }}{\frac{1}{2}}$

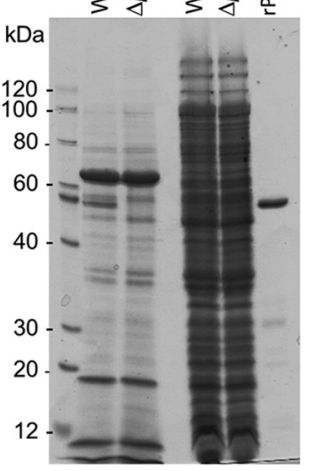

D
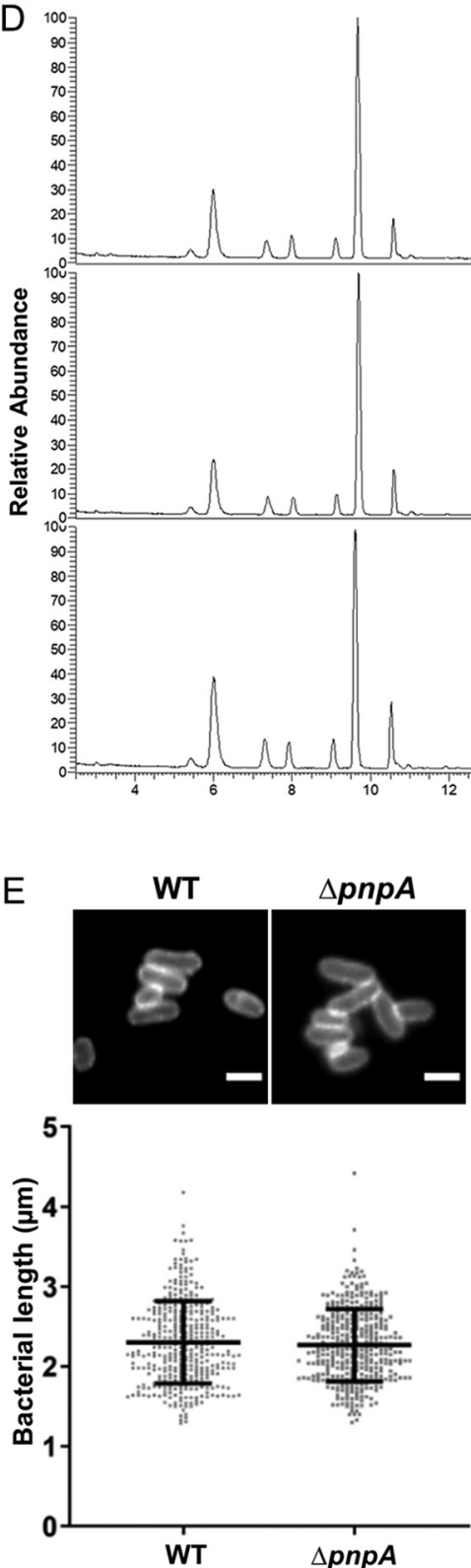

C

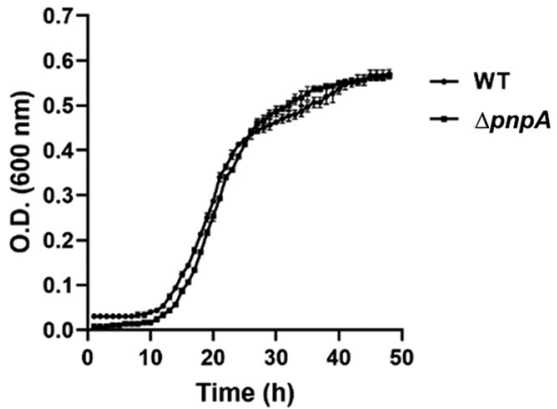
Full ms
[200.0000. 3000.0000 ] MS 415_DR_d5 202002 _MT Wild type

NL: $9.96 E 8$ TC F: FTMS + p ESI Ful $\mathrm{ms}$ [200.0000. 3000.0000 ] MS 20200225_phdp_dnlp
cclone1a_dr_d5 $\triangle p n p A$

(i)

6.67658 TC F: FTMS + $p$ ESI Full $\mathrm{ms}$.

3000.00000 MS cclone 16 _d d d d $d 5$ _dn

$\triangle p n p A$

(ii)

FIG 6 PnpA does not hydrolyze Phdp peptidoglycan. (A) SDS-PAGE of extracellular products (ECPs) and bacterial pellets (Cells) from WT and $\Delta p n p A$ Phdp. ECPs equivalent to $1.5 \mathrm{ml}$ and cells equivalent to $0.3 \mathrm{ml}$ of early stationary culture were separated by $12 \%$ SDS-PAGE

(Continued on next page) 
muropeptides, not present after incubation with inactive $\mathrm{PnpA}^{\mathrm{C324A}}$ or vehicle (Fig. 7; Table 2). V. anguillarum and $V$. vulnificus PG present a very simple muropeptide composition with three major muropeptides, the monomer GM-tetrapeptide (GM4), the dimer GM4-GM4, and the anhydro-dimer (GM4-GanhM4 and GanhM4-GM4). The high proportion of anhydro-muropeptides indicates that $V$. vulnificus has a PG with short glycan chains (Table 2). PnpA treatment led to the appearance of four new muropeptides, GM2, GanhM2, GM4-mDapA, and GanhM4-mDapA. GM2 and GanhM2 products are consistent with the hydrolysis of the $\gamma$-D-glutamyl-meso-diaminopimelic acid bond. The presence of GM4-mDapA and GanhM4-mDapA are also consistent with the hydrolysis of a dimer or higher oligomers such as the major dimers GM4-GM4 and GM4-GanhM4 and the trimers GM3-GM4-GM4 and GM4-GM4-GM4 (Table 2) at the $\gamma$-D-glutamyl-mesodiaminopimelic acid bond at one of the 4-amino-acid stem peptides.

Analysis of the products released from the $V$. vulnificus PG identified two main tetrasaccharides substituted with the L-alanine-D-glutamate dipeptide (GM2-GanhM2) and/ or a remain of the dimer cross-link (GM4-GanhM4-mDapA; Fig. 7 and Fig. S6; Table 3). Additionally, the GanhM2 monomer, the remains of the monomer stem peptide $\mathrm{mDapA}$ and of dimer cross-link mDapA-mDapA were also released, confirming that PnpA is indeed a $\gamma$-D-glutamyl-meso-diaminopimeate endopeptidase (Fig. 7 and Fig. S6; Table 3).

In order to assess whether PnpA could inhibit the growth of competitor bacteria, the growth of $V$. vulnificus was monitored in the presence of PnpA ( $5 \mu \mathrm{g} \mathrm{ml}^{-1}$ ), and no growth inhibition was observed (Fig. S7A). To test the hypothesis that an additional factor secreted by Phdp could assist PnpA in reaching the PG, the growth of $V$. vulnificus was monitored in the presence of ECPs from wild-type or $\Delta p n p A$ Phdp (Fig. S7B) and in coculture experiments (Fig. S7C). No growth inhibition was observed in any of these experiments. Finally, it was tested whether PnpA was able to inhibit the growth of $V$. vulnificus in the presence of EDTA, an external membrane-permeabilizing agent used to mimic conditions that may be encountered in the host, and no effect on growth was observed (Fig. S7D).

\section{DISCUSSION}

In this work, the structural and functional characterization of PnpA, an NIpC/P60 family peptidase secreted by Photobacterium damselae subsp. piscicida (Phdp) is reported. PnpA is not essential for Phdp cell wall biogenesis and does not cleave Phdp PG, but it degrades the PG of $V$. anguillarum and $V$. vulnificus, two bacterial species that share the same hosts and/or environment as Phdp. On the basis of these observations, it is proposed that PnpA may allow Phdp to fight competitors or to acquire nutrients from dead coinhabitants.

Many cysteine peptidases containing the NIpC/P60 domain were characterized thus far $(1,2,24,26,30,33-35)$, several of which display a four-domain organization similar to PnpA. However, until now, only the three-dimensional structure of DvLysin from Desulfovibrio vulgaris was reported, with a N-terminal "c-clip" or "N_NLPC_P60" stabilizing domain, two SH3b domains, and a C-terminal NIpC/P60 cysteine peptidase domain (26). Furthermore, among the known DvLysin and PnpA orthologs, only EcgA from

FIG 6 Legend (Continued)

and stained with Coomassie blue. Recombinant PnpA (rPnpA; $2 \mu \mathrm{g}$ ) was used as a reference. The gel shown is representative of two independent experiments. (B) Western blotting detection of PnpA in WT and $\triangle p n p A$ strains (top panel; ECPs and cells equivalent to $0.3 \mathrm{ml}$ of culture). rPnpA $(0.2 \mu \mathrm{g})$ was used as a control. The bottom panel shows total protein loading (Ponceau S). The blot shown is representative of three independent experiments. (C) Deletion of pnpA does not affect bacterial growth. Phdp MT1415 and MT1415 strains were grown in TSB-1 at $25^{\circ} \mathrm{C}$. Growth curves were generated from three replicates for each strain. The results shown are representative of two independent experiments. (D) Total ion current (TIC) of digested and reduced PG from wild-type Phdp MT1415 (top) and MT1415 does not affect bacterial morphology. Bacteria labeled with wheat germ agglutinin (WGA)-Alexa Fluor 488 (top panel; bars, $2 \mu \mathrm{m}$ ). The lengths of at least 150 bacteria from two independent experiments were measured and graphed (bottom panel, mean length \pm standard deviation [SD] [error bar]). Statistical significance was tested by Student's $t$ test, and no differences were observed. (F) Total ion current (TIC) of digested and reduced PG of Phdp previously incubated with vehicle, PnpA, or catalytically inactive PnpA ${ }^{\mathrm{C} 324 \mathrm{~A}}$; the corresponding reduced supernatants are shown in Fig. $\mathrm{S} 6$ in the supplemental material. 


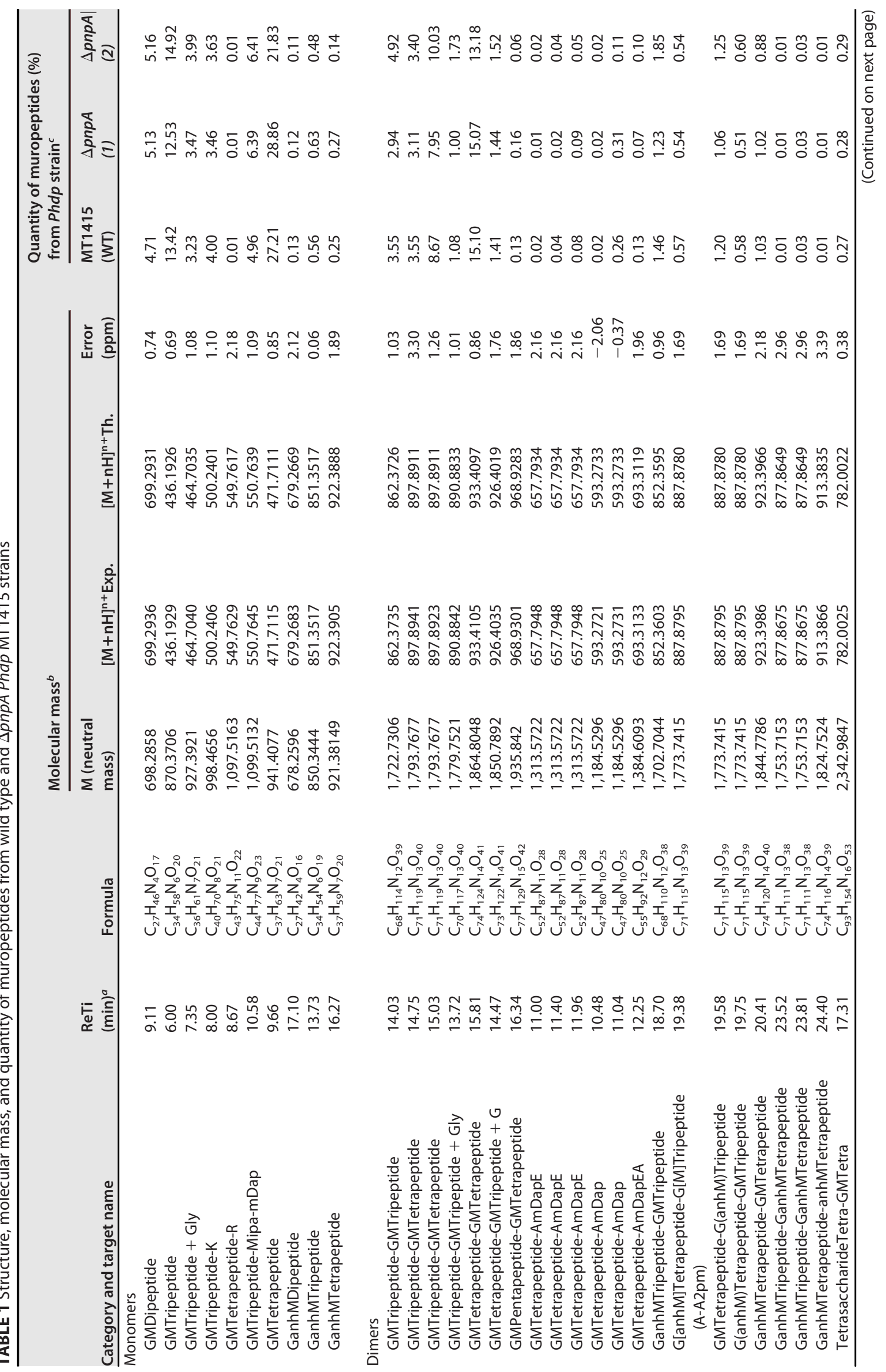




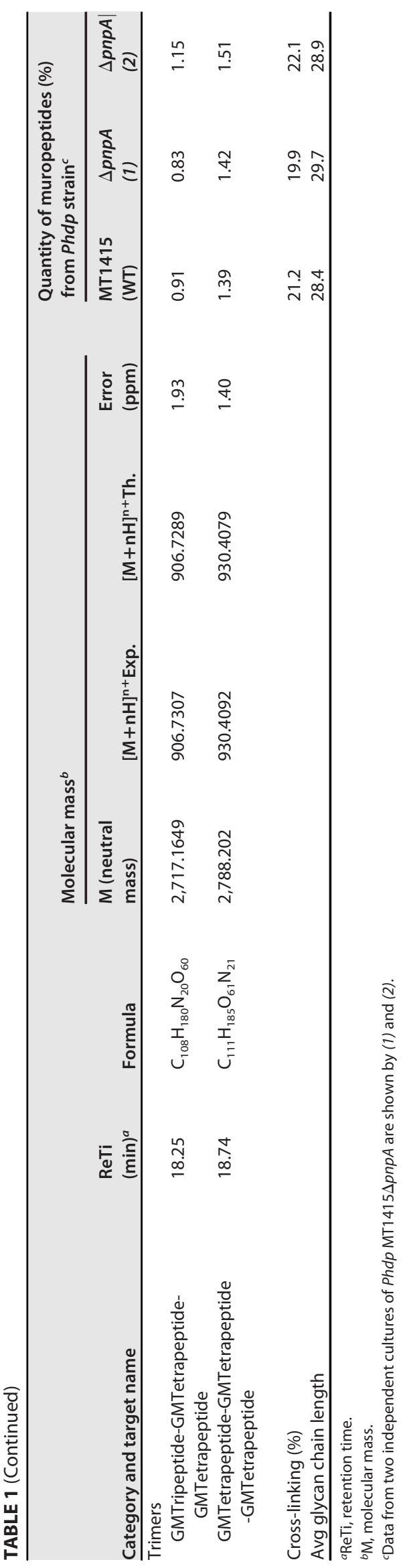




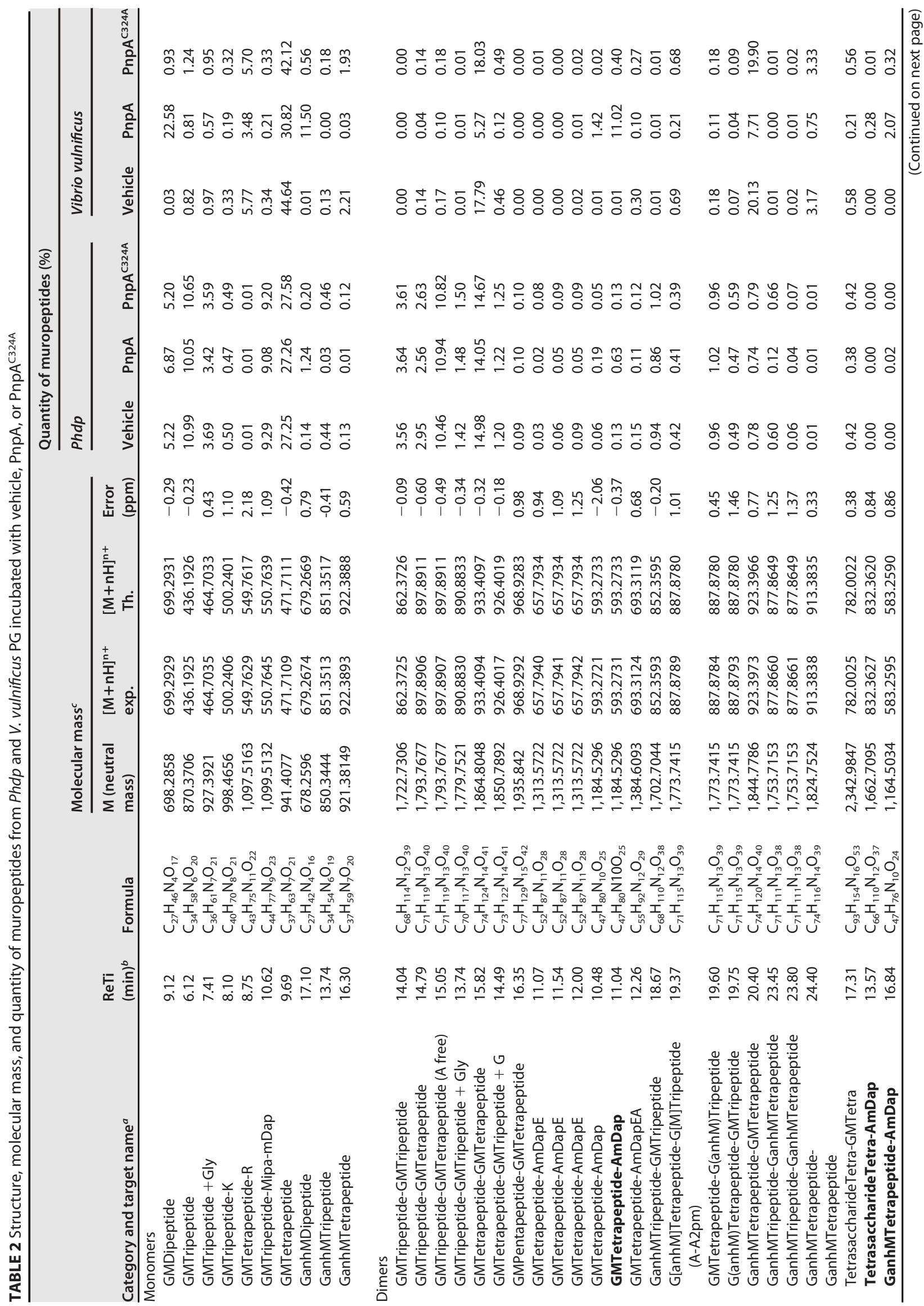




$$
\mathbb{L}
$$




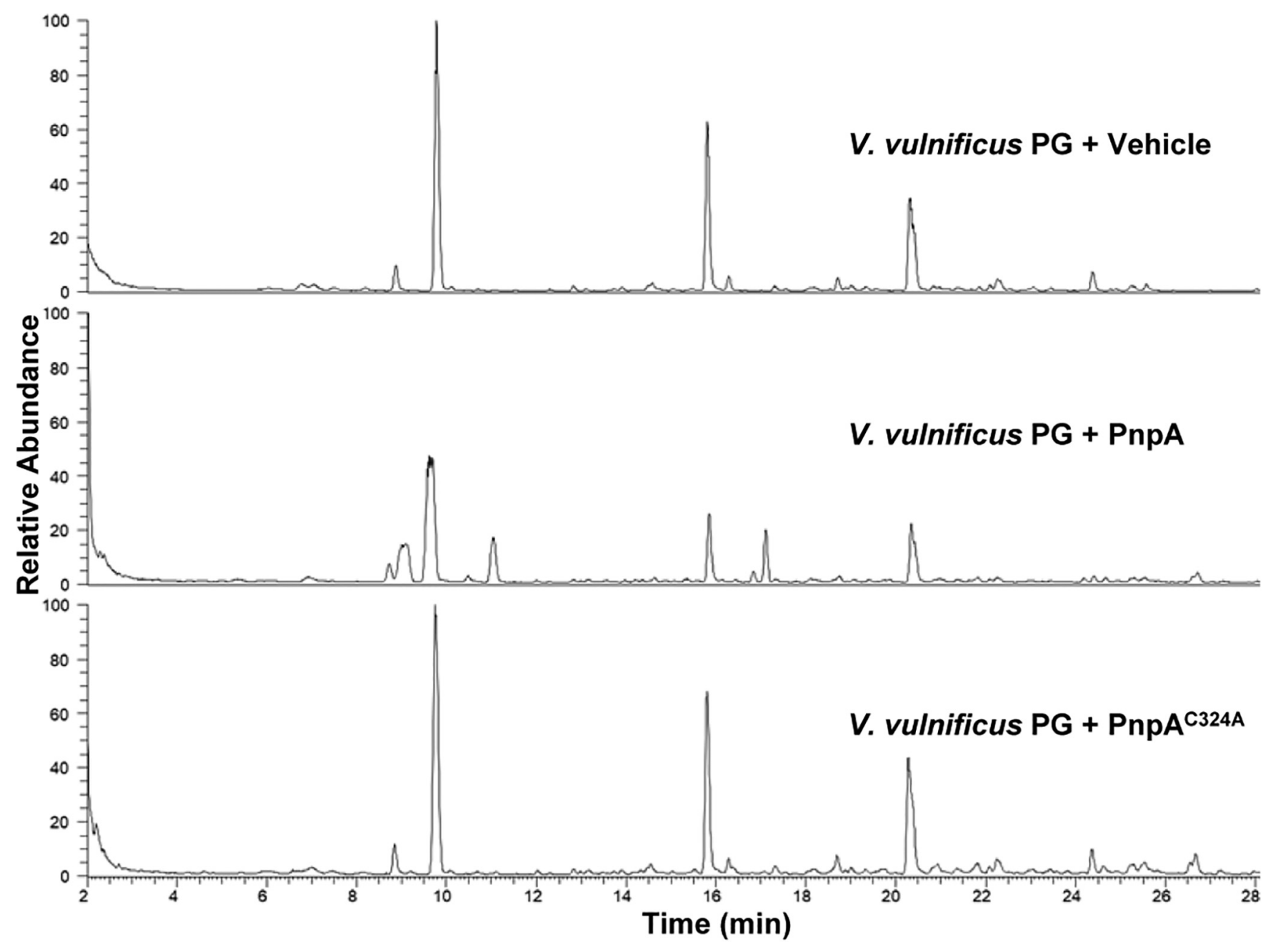

FIG 7 Total ion current (TIC) of digested and reduced PG of V. vulnificus previously incubated with vehicle, PnpA, or catalytically inactive PnpA $324 \mathrm{~A}$; the corresponding reduced supernatants are shown in Fig. S6.

Salmonella enterica serovar Typhimurium was functionally characterized (56). Although the three molecules are very similar ( 25 to $27 \%$ amino acid sequence identity) (see Fig. S8A in the supplemental material), DvLysin does not have the insertion found in PnpA and EcgA and that in PnpA closes the side of the catalytic groove opposed to the RT loop (Fig. 2 and 3 and Fig. S8B). Despite these differences, residues involved in substrate binding in DvLysin (26) are conserved in PnpA and EcgA (Fig. 3C and Fig. S8B), in agreement with their specificity for the $\gamma$-D-glutamyl-meso-diaminopimelic acid bond (Fig. 5) (26, 56). However, unlike DvLysin (26) and EcgA (56), which were more active toward tetra- and trimuropeptides, respectively, PnpA showed activity toward penta-, tetra-, and tripeptides (Fig. 5).

So far, the cellular localization of DvLysin and its function in D. vulgaris cell wall biogenesis remain unknown (26). Regarding EcgA, its expression is induced when $S$. Typhimurium is inside eukaryotic cells, localizing in the inner and outer membranes where it plays a role in PG remodeling and contributes to $S$. Typhimurium virulence (56). In contrast, PnpA is secreted by the T2SS into the extracellular medium (Fig. 4), and deletion of pnpA does not affect Phdp growth, PG composition, and morphology (Fig. 6C to E). Accordingly, PnpA has no in vitro hydrolytic activity toward Phdp sacculi (Fig. 6F and Fig. S5A). Altogether, these results suggest that PnpA is not involved in Phdp cell wall biogenesis.

The resistance of Phdp PG to the activity of PnpA is in sharp contrast with the ability of PnpA to hydrolyze penta-, tetra-, and trimuropeptides, since the chemical composition 
TABLE 3 Analysis of PG reduced supernatants from Phdp and Vibrio vulnificus after incubation with PnpA

\begin{tabular}{|c|c|c|c|c|c|c|c|c|}
\hline \multirow[b]{2}{*}{ Target name } & \multirow[b]{2}{*}{$\begin{array}{l}\text { ReTi } \\
\text { (min) }\end{array}$} & \multirow[b]{2}{*}{ Formula } & \multicolumn{4}{|c|}{ Molecular mass } & \multicolumn{2}{|c|}{ Supernatant ${ }^{a}$} \\
\hline & & & $\begin{array}{l}M \text { (neutral } \\
\text { mass) }\end{array}$ & {$[\mathrm{M}+\mathrm{nH}]^{\mathrm{n}+}$ exp. } & {$[M+n H]^{n+T h}$.} & $\begin{array}{l}\text { Error } \\
\text { (ppm) }\end{array}$ & $\begin{array}{l}\text { Phdp PG + } \\
\text { PnpA }\end{array}$ & $\begin{array}{l}\text { V. vulnificus + } \\
\text { PnpA }\end{array}$ \\
\hline mDap-Alanine $+\mathrm{H}_{2} \mathrm{O}$ & 2.11 & $\mathrm{C}_{10} \mathrm{H}_{19} \mathrm{~N}_{3} \mathrm{O}_{5}$ & 261.1325 & 262.1391 & 262.1398 & -2.67 & $4.20 \mathrm{E}+06$ & $6.95 \mathrm{E}+07$ \\
\hline $\begin{array}{c}\text { mDap-Alanine-mDap- } \\
\text { Alanine }+\mathrm{H}_{2} \mathrm{O}\end{array}$ & 2.27 & $\mathrm{C}_{20} \mathrm{H}_{36} \mathrm{~N}_{6} \mathrm{O}_{9}$ & 504.2544 & 505.2610 & 505.2617 & -1.39 & $8.84 \mathrm{E}+06$ & $1.41 \mathrm{E}+09$ \\
\hline \multicolumn{9}{|l|}{ Nonreduced } \\
\hline GanhMDipeptide & 18 & $\mathrm{C}_{27} \mathrm{H}_{42} \mathrm{~N}_{4} \mathrm{O}_{16}$ & 678.2596 & 679.2674 & 679.2669 & 0.74 & $2.99 \mathrm{E}+08$ & $5.29 E+08$ \\
\hline GanhMTetrapeptide & 17.25 & $\mathrm{C}_{37} \mathrm{H}_{59} \mathrm{~N}_{7} \mathrm{O}_{20}$ & 921.38149 & 922.3893 & 922.3888 & 0.55 & $0.00 E+00$ & $0.00 E+00$ \\
\hline $\begin{array}{l}\text { GM(Dipeptide)- } \\
\text { GanhMTetrapeptide- } \\
\text { mDapA-mDapA }\end{array}$ & 20.36 & $\mathrm{C}_{84} \mathrm{H}_{135} \mathrm{~N}_{17} \mathrm{O}_{44}$ & $2,085.885$ & $1,043.9495$ & $1,043.9497$ & -0.19 & $0.00 \mathrm{E}+00$ & $2.31 E+08$ \\
\hline $\begin{array}{l}\text { GM(Dipeptide)- } \\
\quad \text { GanhMTetrapeptide-mDapA }\end{array}$ & 21.64 & $\mathrm{C}_{74} \mathrm{H}_{118} \mathrm{~N}_{14} \mathrm{O}_{40}$ & $1,842.763$ & 922.3888 & 922.3888 & 0.00 & $0.00 \mathrm{E}+00$ & $2.90 E+08$ \\
\hline $\begin{array}{l}\text { GM(Dipeptide)- } \\
\text { GanhMDipeptide }\end{array}$ & 22.84 & $\mathrm{C}_{54} \mathrm{H}_{84} \mathrm{~N}_{8} \mathrm{O}_{32}$ & $1,356.5192$ & 679.2655 & 679.2669 & -2.06 & $0.00 \mathrm{E}+00$ & $4.95 E+09$ \\
\hline $\begin{array}{l}\text { GM(Dipeptide)-GM(Dipeptide)- } \\
\text { GanhMDipeptide }\end{array}$ & 25.95 & $\mathrm{C}_{81} \mathrm{H}_{126} \mathrm{~N}_{12} \mathrm{O}_{48}$ & $2,034.7787$ & $1,018.3970$ & $1,018.3967$ & 0.29 & $2.94 \mathrm{E}+05$ & $3.57 E+08$ \\
\hline
\end{tabular}

aValues indicate the intensity of the corresponding muropeptide by mass spectrometry analysis in arbitrary units.

of Phdp PG suggested that it would be a target of PnpA. This unexpected resistance to PnpA was not exclusively observed with PG from Phdp, as it also occurred when using sacculi from multiple bacterial species (Fig. S5). In fact, PGs from $V$. anguillarum and $V$. vulnificus were sensitive to the activity of PnpA, despite having a PG composition characteristic of Gram-negative bacteria and similar to the composition of some PG shown to be resistant to PnpA hydrolysis. Hence, PnpA specificity for $V$. anguillarum and V. vulnificus PG cannot be explained by their muropeptide composition and may be related to specific three-dimensional features of the PG mesh. Accordingly, the analysis of the $V$. anguillarum and $V$. vulnificus $P G$ composition shows that these two species have a high proportion of anhydro-muropeptides, a trademark of the end of glycans, indicating that their glycan chains are rather short compared to other Gram-negative bacteria. Consequently, structural analysis of the products released upon incubation of the sacculi of $V$. anguillarum and $V$. vulnificus with PnpA identified a high proportion of the tetrasaccharide GM2-GanhM2. This suggests that the PG of $V$. anguillarum and $V$. vulnificus is enriched in tetrasaccharides. The simultaneous release of $\mathrm{mDapA}-\mathrm{mDapA}$ suggests that these tetrasaccharides are linked to the rest of the PG by one or even two cross-links. These results combined with the rather simple muropeptide composition of $V$. anguillarum and $V$. vulnificus suggest that the vulnerability of $V$. anguillarum and $V$. vulnificus to PnpA might arise from the fact that their PGs rely on very short, highly cross-linked glycans. Hence, hydrolysis of the stem peptides by PnpA leads to a rapid destruction of the PG layer while in other Gram-negative species, because they have much longer glycans, PG integrity can be maintained by multiple dimers along the same glycan chain (Fig. 8).

Expression levels of $p n p A$ in standard culture conditions do not vary between the logarithmic and stationary growth phases (Fig. S1) but increase under iron-limited conditions or in response to oxidative stress (57). However, in vivo, no changes in pnpA expression were detected after intraperitoneal infection of sole (Solea senegalensis) with Phdp (57), and deletion of $p n p A$ did not affect Phdp virulence in a sea bass (Dicentrarchus labrax) intraperitoneal infection model (Fig. S7E). This suggests that PnpA is likely dispensable at late systemic phases of Phdp infection but does not exclude a role of PnpA in earlier stages of the infection. It is known that, during the systemic phase of Phdp-induced disease, the exotoxin AIP56 plays a major role by neutralizing host phagocytic defenses $(43-45,47,58)$. However, little is known about the early stages of the infection. Here, it is shown that PnpA specifically hydrolyzes the sacculi of V. anguillarum and V. vulnificus (Fig. 7, Fig. S5B and C, and Fig. S6), two other 
A

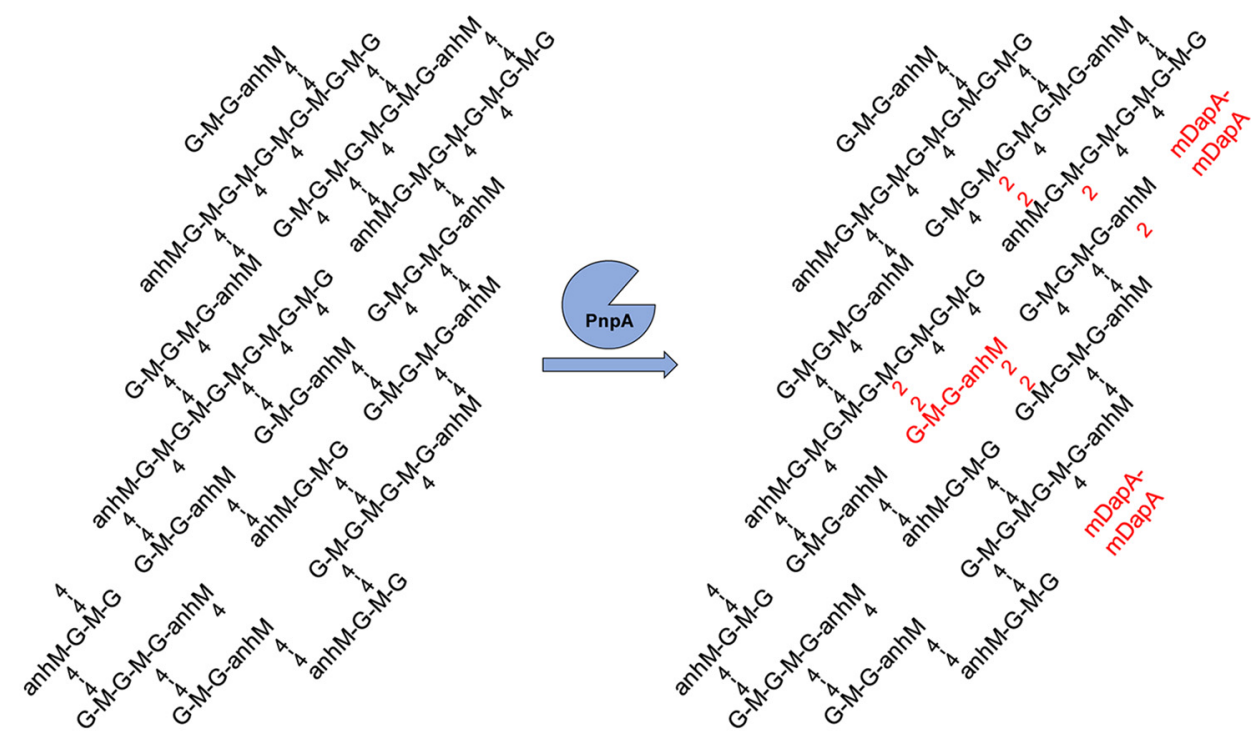

B

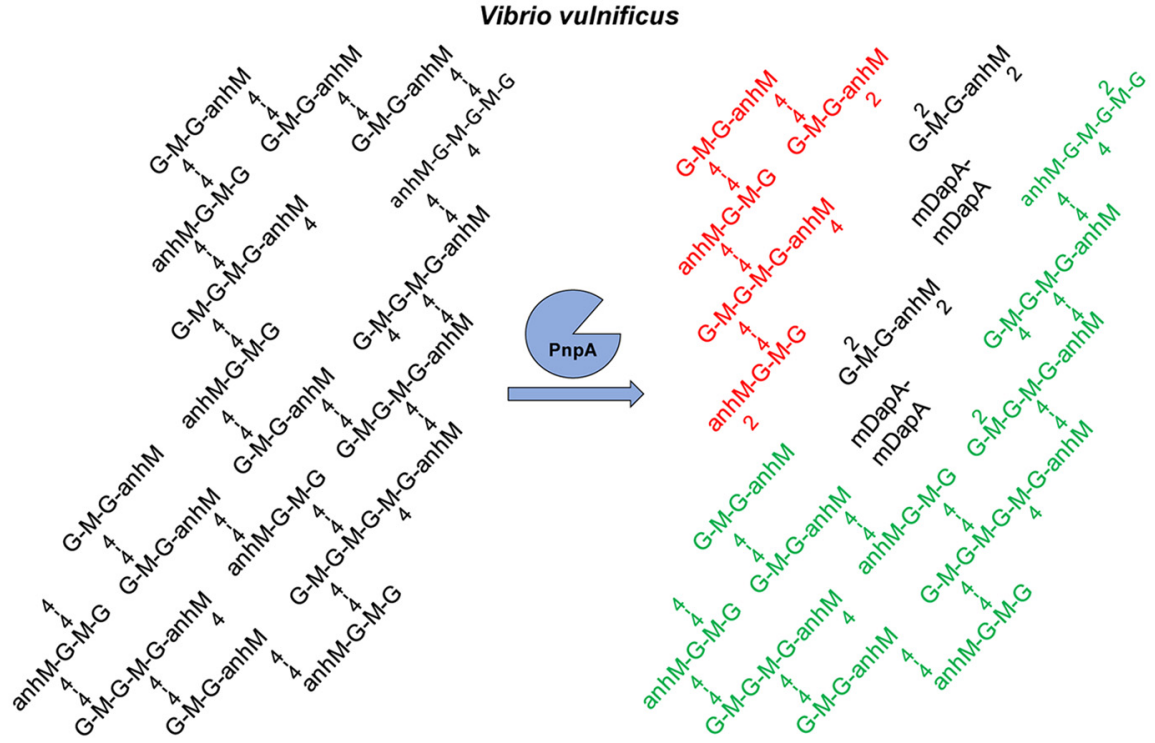

FIG 8 Structural model of Phdp (A) and V. vulnificus (B) PG suggesting that the higher degree of cross-linking of very short glycans in the $V$. vulnificus PG may explain its vulnerability to the enzymatic activity of PnpA.

enterobacteria present in the marine environment (59-61) and, at least in the case of V. anguillarum, reported as infecting the same hosts as Phdp $(37,61)$. This suggests that before reaching the systemic phase, Phdp may secrete PnpA to gain competitive growth advantage over bacteria sharing a complex community environment, such as the gastrointestinal tract, or to obtain nutrients in an environment where nutrient scarcity can compromise its survival, either inside the host or in water or sediment (40). These strategies have been first described for Gram-positive bacteria $(21,23)$, which have their PG exposed on the cell surface, accessible to secreted PG hydrolases $(10,11$, 22). Gram-negative bacteria, despite having their PG protected by the outer membrane, can inject PG hydrolases, including NIpC/P60 family peptidases, into the periplasm of neighboring bacteria through type $\mathrm{VI}$ secretion systems $(10,17,19,20)$. The examples of using bacterial exohydrolases to target Gram-negative competitors are restricted to predatory bacteria such as myxobacteria (11) and Bdellovibrio bacteriovorus (18). Another example where PG hydrolases are secreted to eliminate competing 
bacteria is that reported for the urogenital pathogenic protozoan Trichomonas vaginalis (16), which has acquired by lateral genetic transfer two genes of bacterial origin encoding NIpC/P60 endopeptidases that the parasite secretes to degrade bacterial PG and thus outcompete bacteria from mixed cultures (16). However, it remains unclear how these exohydrolases reach the PG of the Gram-negative targets. Here, it was also not clarified how PnpA reaches the PG in V. vulnificus and $V$. anguillarum cell wall, since no growth inhibition was detected in several in vitro tests with V. vulnificus (Fig. S7), suggesting that the access of PnpA to the periplasm of competing bacteria may depend on conditions present at specific stages of the Phdp life cycle, when Phdp and competitors meet.

\section{MATERIALS AND METHODS}

Bacterial strains and culture conditions. Photobacterium damselae subsp. piscicida (Phdp) virulent strain MT1415 isolated from sea bass in Italy (45) was cultured at $25^{\circ} \mathrm{C}$ in tryptic soy broth (TSB) or tryptic soy agar (TSA) supplemented with $\mathrm{NaCl}$ to a final concentration of $1 \%$ (wt/vol) (TSB-1 and TSA-1, respectively). The $\Delta e p s L$ and $\Delta p n p A$ strains were cultured under the same conditions as the wild type. $\Delta e p s L+$ pEpsL and $\Delta p n p A+$ pPnpA complemented strains were cultured in TSB-1 or TSA-1 supplemented with $10 \mu \mathrm{g} \mathrm{ml}^{-1}$ of gentamicin (TSB-1 ${ }_{\mathrm{Gm}}$ and TSA-1 ${ }_{\mathrm{Gm}}$, respectively). Stocks of bacteria were maintained at $80^{\circ} \mathrm{C}$ in TSB-1 supplemented with $15 \%$ (vol/vol) glycerol. To obtain growth curves, bacteria grown on agar plates for $48 \mathrm{~h}$ were suspended in TSB-1 or TSB-1 ${ }_{\mathrm{Gm}}$ at an optical density at $600 \mathrm{~nm}\left(\mathrm{OD}_{600}\right)$ of 0.5 to 0.6 . These suspensions were inoculated in $20 \mathrm{ml}$ TSB-1 (1:100 dilution). One-milliliter aliquots were removed (in triplicate) and transferred to 24-well culture plate, and the $\mathrm{OD}_{600}$ was determined kinetically (1 point/h) using a BioTek Synergy 2 spectrofluorometer (BioTeK U.S., Winooski, VT, USA) at $25^{\circ} \mathrm{C}$ with continuous slow agitation, for 60 to $70 \mathrm{~h}$. Growth curves were constructed using GraphPad Prism software (La Jolla, CA, USA).

Construction of $\Delta p n p A$ strain. An in-frame (nonpolar) deletion of the almost complete pnpA coding sequence was constructed following an allelic exchange procedure as previously described (62). In brief, the $3^{\prime}$ and $5^{\prime}$ flanking sequences were PCR amplified using suitable primers (Mut_NlpC_1Eco [5'GCGAATTCGTTTCGATGCGCTGATTAAT-3'], Mut_NIpC_2Bam [5'-GCGGATCCAGCAAAACATCAACAAGTCA-3'], Mut_NIpC_3Bam [5'-GCGGATCCATAGTTGGTTAATAATGCTA-3'], and Mut_NlpC_4Xba [5'-GCTCTAGATCACGATGGAATAGATAACT-3'] [restriction sites are underlined]). The PCR products were ligated to obtain an inframe deletion of ca. $90 \%$ of the PnpA coding sequence. The deleted allele construction was cloned into the suicide vector pNidKan containing the $s a c B$ gene, which confers sucrose sensitivity, and R6K ori, which requires the pir gene product for replication. The plasmid containing the deleted allele was transferred from Escherichia coli S17-1- $\lambda$ pir into the rifampin-resistant derivative of Phdp MT1415 by drop mating for $24 \mathrm{~h}$ on TSA plates prepared with seawater. Cells were then scrapped off the plate and selected on TSA supplemented with kanamycin (Kan) $\left(50 \mu \mathrm{g} \mathrm{ml}^{-1}\right)$ for plasmid integration. A selected Kan ${ }^{r}$ clone was further selected for sucrose resistance (15\% [wt/vol]) for a second recombination event. This led to Phdp $\Delta p n p A$ mutant strain, which was tested by PCR to verify the correct allelic exchange.

Bacterial cell extracts and extracellular products. Phdp was grown in TSB- 1 at $25^{\circ} \mathrm{C}$ with shaking (160 rpm) and centrifuged $\left(6,000 \times g, 5 \mathrm{~min}, 4^{\circ} \mathrm{C}\right)$, and the pellets (total cell extracts) and culture supernatants were collected. Supernatants were filtered $(0.22 \mu \mathrm{m})$ to obtain extracellular products (ECPs). For SDS-PAGE, proteins in the ECPs were precipitated with trichloroacetic acid (TCA) as previously described (45).

PnpA identification. ECPs from Phdp strain MT1415 were subjected to SDS-PAGE followed by Coomassie blue staining. A protein band of approximately $55 \mathrm{kDa}$ was analyzed by MALDI-TOF MS in a 4800 Proteomics Analyzer (Applied Biosystems) at TOPLAB GmbH. The MS data were used for a Mascot search against the NCBInr sequence database.

Draft genome sequence of Phdp MT1415 and genomic context of pnpA locus. To delete the PnpA-encoding gene in Phdp MT1415, it was necessary to obtain at least $2 \mathrm{~kb}$ of upstream and downstream sequences free of repetitive insertion sequence elements that would compromise the specific recombination steps during allelic exchange. Therefore, the draft genome sequence of strain MT1415 was obtained, using an Illumina platform as previously described (48) and deposited in the GenBank database under accession number SUMH00000000. A comparative analysis was conducted by retrieving the genomic contexts of pnpA genes in different Phdp and Photobacterium damselae subsp. damselae (Phdd) isolates whose draft or complete genomes are available in the GenBank database. The GenBank locus tag numbers of the pnpA homologues used in this analysis are VDA_000779 (Phdd type strain CIP 102761), PDPUS_2_00834 (Phdp 91-197), PDPJ_2_00460 (Phdp OT-51443), BEl67_17705 (Phdp L091106-03H), and BDMQ01000002 (Phdp DI21). For the pnpA negative Phdd strain RM-71, the draft genome sequence as a source of homologous flanking DNA sequences was used (accession number NZ_LYBT00000000.1). The DNA sequences were handled with Vector NTI 10.3.0 sequence editor (Invitrogen).

Recombinant PnpA. The pnpA open reading frame (ORF) (GenBank accession number TJZ86030.1) was amplified from Phdp MT1415 genomic DNA using Pfu DNA polymerase (Thermo Scientific) and primers 5'-cgccATGGATATAAATAAACATTAATGC-3' and 5'-gcgctcgag TITTCAAATAGATATTITC-3' (target sequences are in uppercase letters) and cloned into $\mathrm{pET} 28 \mathrm{a}(+)$ using the $\mathrm{Ncol}$ and Xhol restriction sites, in frame with a $\mathrm{C}$-terminal $6 \times \mathrm{His}$ tag. Mutation of $\mathrm{C}^{324}$ to alanine was achieved by site-directed 
mutagenesis by inverse PCR using Q5 high fidelity DNA polymerase (New England BioLabs), pET28-PnpA as the template, and primers (5'-GCCTCTGGTTATTAAAAAGGTTATTCAGC-3' and 5'-ATCATTATTGAAATCCATTCCCCC-3'). Proteins were expressed in E. coli BL21(DE3) CodonPlus-RIL (Stratagene). Four liters of LB medium with $50 \mu \mathrm{g} \mathrm{ml}^{-1}$ kanamycin and $25 \mu \mathrm{g} \mathrm{ml}^{-1}$ chloramphenicol were inoculated with PET28-PnPA-

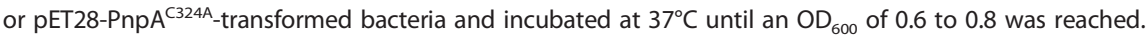
Cultures were cooled at $17^{\circ} \mathrm{C}$ for $30 \mathrm{~min}$, followed by the addition of $0.5 \mathrm{mM}$ isopropyl- $\beta$-D-thiogalactopyranoside (IPTG) to induce protein expression. After $20 \mathrm{~h}$, cells were harvested by centrifugation, resuspended in $50 \mathrm{mM}$ Bis-Tris $(\mathrm{pH} 6.5)$ and $500 \mathrm{mM} \mathrm{NaCl}$, and sonicated. Lysates were centrifuged $(34,957 \times g$, $30 \mathrm{~min}, 4^{\circ} \mathrm{C}$ ), and the soluble fraction was applied to a nickel-nitrilotriacetic acid (Ni-NTA) column (ABT), followed by anion-exchange chromatography (Bio-Scale Mini Macro-Prep High Q; Bio-Rad). Fractions containing the recombinant proteins were pooled and injected into a size exclusion chromatography column (Superose12 10/300 GL; GE Healthcare) equilibrated with $50 \mathrm{mM}$ Bis-Tris (pH 6.5) and $500 \mathrm{mM} \mathrm{NaCl}$. Fractions containing the desired protein were pooled, concentrated to 6 to $7 \mathrm{mg} \mathrm{ml}^{-1}$, frozen in liquid nitrogen, and stored at $-80^{\circ} \mathrm{C}$. Protein concentration was determined in a NanoDrop ND-1000 UV-visible (UV-Vis) spectrophotometer (Thermo Fisher Scientific) considering the extinction coefficient and the molecular weight calculated with the ProtParam tool (https://web.expasy.org/protparam/).

Reverse transcription and quantitative PCR (qRT-PCR). Total RNA was isolated from exponential $\left(\mathrm{OD}_{600}\right.$ of 0.4$)$ and stationary $\left(\mathrm{OD}_{600}\right.$ of 1.2) cultures of Phdp strain MT1415. Bacterial pellets were resuspended in $25 \mathrm{mM}$ Tris buffer supplemented with $20 \%$ (wt/vol) glucose and $0.5 \mathrm{M}$ EDTA (pH 8.0) and lysed with phenol acid and glass beads by vortexing $\left(4^{\circ} \mathrm{C}, 20 \mathrm{~min}\right)$. Lysates were centrifuged at $16,000 \times$ $g\left(4^{\circ} \mathrm{C}, 5 \mathrm{~min}\right)$, and the top liquid phase was collected. RNA was extracted using the TripleXtractor reagent (Grisp) and treated with DNase I (Turbo DNA-free; Ambion) following the manufacturer's recommendations. RNA purity and integrity were verified by $1 \%(\mathrm{wt} / \mathrm{vol})$ agarose gel electrophoresis in an Experion automated electrophoresis system (Bio-Rad). One microgram of RNA was reverse transcribed into CDNA (iScript kit; Bio-Rad). Quantitative real-time PCR was performed in 20- $\mu$ l reaction mixtures containing $1 \mu \mathrm{l} \mathrm{CDNA}, 10 \mu \mathrm{l}$ iTaq Universal SYBR green Supermix (Bio-Rad Laboratories), and $0.25 \mu \mathrm{M}$ primers (PnpA forward primer [5'-GGATTTGGCTACCTCGTTCA-3'], PnpA reverse primer [5'-CCCACGGAGCATTAAACATT-3'], 16S forward primer [5'-AACTGGCAGGCTAGAGTCTT-3'], and $16 \mathrm{~S}$ reverse primer [5'CACAACCTCCAAGTAGACAT- $3^{\prime}$ )), using the following protocol: 1 cycle at $95^{\circ} \mathrm{C}(3 \mathrm{~min})$ and 40 cycles with 1 cycle consisting of $95^{\circ} \mathrm{C}(20 \mathrm{~s}), 51^{\circ} \mathrm{C}(15 \mathrm{~s})$, and $72^{\circ} \mathrm{C}(30 \mathrm{~s})$. For each condition, three biological replicates were analyzed, each of which had three technical replicates. Data were normalized to the expression values of the housekeeping gene (16S rRNA) and analyzed by the comparative threshold $\left(\Delta \Delta C_{T}\right)$ method.

Anti-PnpA antibody. The quail anti-PnpA antibody was produced at HenBiotech (catalog no. H003; HenBiotech, Coimbra, Portugal) using recombinant PnpA as the immunizing antigen. Quail lgYs were purified from an egg-yolk pool (IgY grade II/polyethylene glycol [PEG]).

SDS-PAGE and Western blotting. Bacterial cell pellets and ECPs were solubilized in loading buffer (50 mM Tris-HCl [pH 8.8], 2\% [wt/vol] SDS, 0.05\% [wt/vol] bromophenol blue, 10\% [vol/vol] glycerol, $2 \mathrm{mM}$ EDTA, and $100 \mathrm{mM}$ dithiothreitol [DTT]) and subjected to SDS-PAGE (63). Proteins were stained with Coomassie blue or transferred onto nitrocellulose membranes. Transfer efficiency and protein loading were controlled by Ponceau S staining. Membranes were blocked with $5 \%(\mathrm{wt} / \mathrm{vol})$ skim milk in Trisbuffered saline (TBS) containing $0.1 \%$ ( $\mathrm{vol} / \mathrm{vol}$ ) Tween 20 (TBS-T), incubated with the anti-PnpA quail antibody (1:10,000 dilution) in blocking buffer followed by incubation with an anti-chicken alkaline phosphatase-conjugated secondary antibody (catalog no. A9171; Sigma) (1:10,000 dilution) and nitroblue tetrazolium (NBT)/5-bromo-4-chloro-3-indolylphosphate (BCIP) development.

Crystallization. Initial crystallization hits for PnpA were identified by high-throughput screening performed at the HTX Lab of the EMBL Grenoble Outstation (Grenoble, France). Crystallization experiments for refinement of the initial conditions were carried out using the hanging drop vapor diffusion method at $20^{\circ} \mathrm{C}$. Crystals were obtained by mixing protein solution $\left(6.7 \mathrm{mg} \mathrm{ml}^{-1}\right.$ in $50 \mathrm{mM}$ Bis-Tris [pH 6.5 ] and $500 \mathrm{mM} \mathrm{NaCl}$ ) with an equal volume of crystallization solution (100 mM imidazole [pH 8.0], $15 \%$ [wt/vol] polyethylene 8000 [PEG 8K]). Crystals appeared after 24 to $48 \mathrm{~h}$. The crystals were cryo-protected by sequential transfer into their crystallization condition with increasing concentrations of ethylene glycol (up to $30 \%[\mathrm{vol} / \mathrm{vol}]$ ) and then flash-frozen in liquid nitrogen prior to data collection.

Data collection, structure solution, and refinement. Diffraction data were collected at beamline Proxima-1 of Synchrotron SOLEIL (Saint-Aubin, France) (64) on a Dectris Pilatus 6M detector (750 images, $0.2^{\circ}$ rotation, 0.2 -s exposure) and indexed and integrated with XDS (65). Space group determination, data scaling, and merging were performed with POINTLESS and AIMLESS from the CCP4 program suite (66). The structure of PnpA was solved by molecular replacement with Phaser MR as implemented in the CCP4 program suite $(66,67)$ using the coordinates of a putative gamma-D-glutamyl-L-diamino acid endopeptidase from Desulfovibrio vulgaris Hildenborough (DvLysin, PDB entry 3M1U, 26\% sequence identity) as the search model. Phase refinement and initial model building were performed using ARP/WARP (68). Model completion and refinement were done iteratively with COOT (69) and Phenix.refine $(70,71)$, respectively. Refinement and structure validation statistics are summarized in Table S1 in the supplemental material. All illustrations of macromolecular models were produced with PyMOL (72). The experimental data were deposited with the Structural Biology Data Grid (73) under accession number https:// doi.org/10.15785/SBGRID/736.

In vitro muropeptide cleavage assays. To investigate the PnpA enzymatic activity toward PG muropeptides, isolated M3 (GlcNAc-MurNAc-L-Ala-D-Glu-mDAP), M4 (GlcNAc-MurNAc-L-Ala-D-Glu-mDAP-DAla), and M5 (GlcNAc-MurNAc-L-Ala-D-Glu-mDAP-D-Ala-D-Ala) muropeptides from Salmonella enterica were incubated with $50 \mu \mathrm{g}$ of PnpA in $50 \mathrm{mM}$ Tris $\left(\mathrm{pH} \mathrm{8.0)}\right.$ ) and $300 \mathrm{mM} \mathrm{NaCl}$ for $3 \mathrm{~h}$ at $37^{\circ} \mathrm{C}$. The 
products of the reaction were analyzed by reverse-phase HPLC (Waters 1525 system) as previously described (56).

Peptidoglycan (PG) purification. Bacteria were grown in TSB-1 at $25^{\circ} \mathrm{C}$ with shaking $(160 \mathrm{rpm})$ to exponential $\left(\mathrm{OD}_{600}\right.$ of 0.4 to 0.5$)$ or stationary $\left(\mathrm{OD}_{600}\right.$ of 1.2 to 1.4$)$ phases. Bacterial cells $\left(\sim 10^{11}\right)$ were centrifuged $(4,200 \times g, 10 \mathrm{~min}$, room temperature [rt]), washed twice and resuspended in phosphatebuffered saline (PBS), and immediately mixed 1:1 ( $\mathrm{vol} / \mathrm{vol})$ with a boiling solution of $8 \%$ SDS, drop by drop. Boiling was maintained for $8 \mathrm{~h}$ with stirring, followed by overnight incubation at rt. Samples were centrifuged $\left(150,000 \times \mathrm{g}, 40 \mathrm{~min}, 4^{\circ} \mathrm{C}\right)$, the pellets were washed three times with ultrapure water $\left(150,000 \times g, 40 \mathrm{~min}, 4^{\circ} \mathrm{C}\right)$, resuspended in $10 \mathrm{mM}$ Tris $(\mathrm{pH} 7.6)$ and $0.06 \%(\mathrm{wt} / \mathrm{vol}) \mathrm{NaCl}$ with or without $100 \mu \mathrm{g} \mathrm{ml}^{-1} \alpha$-amylase, and incubated at $37^{\circ} \mathrm{C}$ for $90 \mathrm{~min}$. Samples were treated for $2 \mathrm{~h}$ at $60^{\circ} \mathrm{C}$ with $100 \mu \mathrm{g} \mathrm{ml}^{-1}$ pronase E preactivated by incubation in the same buffer for $60 \mathrm{~min}$ at $60^{\circ} \mathrm{C}$. Pronase $\mathrm{E}$ digestion was stopped by adding SDS (5.3\% [wt/vol] final concentration) and heating at $100^{\circ} \mathrm{C}$ for $20 \mathrm{~min}$. PG was recovered by centrifugation $(300,000 \times g, 10 \mathrm{~min})$ and washed with ultrapure water.

Analysis of Phdp PG composition and PG cleavage assays. To analyze the PG composition of the Phdp MT1415 and MT1415 DpnpA strains, PGs were purified as described above, digested overnight at $37^{\circ} \mathrm{C}$ in sodium phosphate buffer supplemented with $100 \mathrm{IU}$ of mutanolysin from Streptomyces globisporus (ATCC 21553; Sigma), and reduced with $\mathrm{NaH}_{4} \mathrm{~B}$. After $30 \mathrm{~min}$ at rt and centrifugation, the reduced muropeptides were diluted in acidified water with formic acid (FA) and analyzed by high-performance liquid chromatography (HPLC) or HPLC/high-resolution mass spectrometry (HRMS). HPLC/HRMS was performed on an Ultimate 3000 UHLPC system coupled to a quadrupole orbitrap mass spectrometer (qExactive Focus; Thermo Fisher Scientific). Reduced muropeptides were eluted on an $\mathrm{C}_{18}$ analytical column (Hypersil gold aQ; $1.9 \mu \mathrm{m}, 2.1 \times 150 \mathrm{~mm}$ ) held at $50^{\circ} \mathrm{C}$ under a $200 \mu \mathrm{I} \mathrm{min}^{-1}$ flow rate. A binary solvent system composed of acidified water $\left(\mathrm{H}_{2} \mathrm{O}+0.1 \% \mathrm{FA}\right.$; mobile phase $\left.\mathrm{A}\right)$ and acidified acetonitrile $\left(\mathrm{CH}_{3} \mathrm{CN}+0.1 \% \mathrm{FA}\right.$, mobile phase $\left.\mathrm{B}\right)$ was used for chromatographic separation. The composition was linearly increased to $12.5 \%$ mobile phase B over $25 \mathrm{~min}$, increased to $20 \%$ mobile phase B for $5 \mathrm{~min}$, and held for an additional $5 \mathrm{~min}$. It was then stepped down to $0 \%$ over and held for $10 \mathrm{~min}$ to return initial conditions.

Exactive Focus was operated under electrospray ionization in positive mode and data-dependent acquisition mode (ddMS2) control by Xcalibur 4.0. For structural confirmation of muropeptides, higherenergy collisional dissociation (HCD) fragmentation was set up with a normalized collision energy at 20\%. Data were processed both with the software TraceFinder 3.3 (Thermo Fisher Scientific) and Xcalibur 4.0 for peak area determination.

For testing PnpA activity against macromolecular PG, PGs from Phdp and several bacterial species, purified as described above, were incubated with $100 \mu \mathrm{g} P n p A$ or inactive $\mathrm{PnpA}^{\mathrm{C} 324 \mathrm{~A}}$ at $37^{\circ} \mathrm{C}$ overnight in $50 \mathrm{mM}$ Tris ( $\mathrm{pH} 8.0)$ and $300 \mathrm{mM} \mathrm{NaCl}$. PGs incubated with vehicle were used as controls. After digestion, PGs were analyzed by HPLC or HPLC/HRMS as described above.

Accession number(s). The draft genome sequence of strain MT1415 was obtained and deposited in the GenBank database under accession number SUMH00000000. The experimental data were deposited with the Structural Biology Data Grid (73) under accession number https://doi.org/10.15785/SBGRID/ 736. The structure factors and atomic coordinates of PnpA are deposited in the RCSB Protein Data Bank with accession number 6SQX.

\section{SUPPLEMENTAL MATERIAL}

Supplemental material is available online only.

FIG S1, TIF file, 0.1 MB.

FIG S2, TIF file, 1.3 MB.

FIG S3, TIF file, 0.6 MB.

FIG S4, TIF file, 1.1 MB.

FIG S5, TIF file, 0.5 MB.

FIG S6, TIF file, 0.7 MB.

FIG S7, TIF file, $0.5 \mathrm{MB}$.

FIG S8, TIF file, $2.5 \mathrm{MB}$.

TABLE S1, PDF file, $0.1 \mathrm{MB}$.

TABLE S2, PDF file, $0.2 \mathrm{MB}$.

\section{ACKNOWLEDGMENTS}

We are grateful for access to the HTX crystallization facility (Proposal ID: BIOSTRUCTX_8167). The support of the X-ray Crystallography Scientific Platform of i3S (Porto, Portugal) is also acknowledged.

This work was financed by Fundo Europeu de Desenvolvimento Regional (FEDER) funds through the COMPETE 2020 Operacional Program for Competitiveness and Internationalization (POCI), Portugal 2020, and by Portuguese funds through Fundação para a Ciência e a Tecnologia/Ministério da Ciência, Tecnologia e Ensino Superior (FCT) in the framework of the project POCI-01-0145-FEDER-030018 (PTDC/CVT-CVT/30018/ 
2017). A.D.V. was supported by national funds from Fundação para a Ciência e a Tecnologia (FCT), I.P., within the scope of the Norma Transitória - DL57/2016/CP1355/ CT0010. This work had also support from the State Agency for Research (AEI) of Spain cofunded by the FEDER Program from the European Union (grants AGL2016-79738-R and BIO2016-77639-P) and from the French Government's Investissement d'Avenir program, Laboratoire d'Excellence "Integrative Biology of Emerging Infectious Diseases" (grant ANR10-LABX-62-IBEID; http://www.agence-nationale-recherche.fr/investissements-d-avenir/). A.R. was supported by a postdoctoral fellowship from the Laboratoire d'Excellence "Integrative Biology of Emerging Infectious Diseases" and from an Infec-ERA grant (INTRABACWALL - 16-IFEC-0004-03).

Author contributions are as follows: conceptualization, J.L., A.D.V., and N.M.S.D.S.; data curation, P.J.B.P.; formal analysis, J.L., C.P., J.A., P.J.B.P., F.G.-D.P., I.G.B., A.D.V., and N.M.S.D.S.; funding acquisition, C.R.O., F.G.-D.P., I.G.B., A.D.V., and N.M.S.D.S.; investigation, J.L., C.P., A.R., J.A., M.S.T., A.V.B., I.R., P.J.B.P., C.R.O., F.G.-D.P., I.G.B., and A.D.V.; methodology, J.L., C.R.O., I.G.B., A.D.V., and N.M.S.D.S.; project administration, A.D.V. and N.M.S.D.S.; supervision, P.J.B.P., C.R.O., I.G.B., A.D.V., and N.M.S.D.S.; validation, J. L., P.J.B.P., I.G.B., A.D.V., and N.M.S.D.S.; writing (original draft), J.L., C.R.O., A.D.V., and N.M.S.D.S.; writing (review and editing), J.L., C.P., J.A., P.J.B.P., C.R.O., F.G.-D.P., I.G.B., A.D.V., and N.M.S.D.S.

\section{REFERENCES}

1. Vermassen A, Leroy S, Talon R, Provot C, Popowska M, Desvaux M. 2019. Cell wall hydrolases in bacteria: insight on the diversity of cell wall amidases, glycosidases and peptidases toward peptidoglycan. Front Microbiol 10:331. https://doi.org/10.3389/fmicb.2019.00331.

2. Alcorlo M, Martínez-Caballero S, Molina R, Hermoso JA. 2017. Carbohydrate recognition and lysis by bacterial peptidoglycan hydrolases. Curr Opin Struct Biol 44:87-100. https://doi.org/10.1016/j.sbi.2017.01.001.

3. Juan C, Torrens G, Barceló IM, Oliver A. 2018. Interplay between peptidoglycan biology and virulence in Gram-negative pathogens. Microbiol Mol Biol Rev 82:e00033-18. https://doi.org/10.1128/MMBR.00033-18.

4. Vollmer W, Blanot D, De Pedro MA. 2008. Peptidoglycan structure and architecture. FEMS Microbiol Rev 32:149-167. https://doi.org/10.1111/j .1574-6976.2007.00094.x.

5. Koch AL. 2000. The exoskeleton of bacterial cells (the sacculus): still a highly attractive target for antibacterial agents that will last for a long time. Crit Rev Microbiol 26:1-35. https://doi.org/10.1080/10408410091154165.

6. Irazoki O, Hernandez SB, Cava F. 2019. Peptidoglycan muropeptides: release, perception, and functions as signaling molecules. Front Microbiol 10:500. https://doi.org/10.3389/fmicb.2019.00500.

7. Alvarez L, Espaillat A, Hermoso JA, de Pedro MA, Cava F. 2014. Peptidoglycan remodeling by the coordinated action of multispecific enzymes. Microb Drug Resist 20:190-198. https://doi.org/10.1089/mdr.2014.0047.

8. Johnson JW, Fisher JF, Mobashery S. 2013. Bacterial cell-wall recycling. Ann N Y Acad Sci 1277:54-75. https://doi.org/10.1111/j.1749-6632.2012 .06813.x

9. Vollmer W. 2012. Bacterial growth does require peptidoglycan hydrolases. Mol Microbiol 86:1031-1035. https://doi.org/10.1111/mmi.12059.

10. Wyckoff TJ, Taylor JA, Salama NR. 2012. Beyond growth: novel functions for bacterial cell wall hydrolases. Trends Microbiol 20:540-547. https://doi .org/10.1016/j.tim.2012.08.003.

11. Vollmer W, Joris B, Charlier P, Foster S. 2008. Bacterial peptidoglycan (murein) hydrolases. FEMS Microbiol Rev 32:259-286. https://doi.org/10 $.1111 /$ j.1574-6976.2007.00099.x

12. Park JT, Uehara T. 2008. How bacteria consume their own exoskeletons (turnover and recycling of cell wall peptidoglycan). Microbiol Mol Biol Rev 72:211-227. https://doi.org/10.1128/MMBR.00027-07.

13. Jacobs C, Huang LJ, Bartowsky E, Normark S, Park JT. 1994. Bacterial cell wall recycling provides cytosolic muropeptides as effectors for beta-lactamase induction. EMBO J 13:4684-4694. https://doi.org/10.1002/j.1460 -2075.1994.tb06792.x

14. Boudreau MA, Fisher JF, Mobashery S. 2012. Messenger functions of the bacterial cell wall-derived muropeptides. Biochemistry 51:2974-2990. https://doi.org/10.1021/bi300174x.

15. Keep NH, Ward JM, Cohen-Gonsaud M, Henderson B. 2006. Wake up!
Peptidoglycan lysis and bacterial non-growth states. Trends Microbiol 14:271-276. https://doi.org/10.1016/j.tim.2006.04.003.

16. Pinheiro J, Biboy J, Vollmer W, Hirt RP, Keown JR, Artuyants A, Black MM, Goldstone DC, Simoes-Barbosa A. 2018. The protozoan Trichomonas vaginalis targets bacteria with laterally acquired NIpC/P60 peptidoglycan hydrolases. mBio 9:e01784-18. https://doi.org/10.1128/mBio.01784-18.

17. Chou S, Bui NK, Russell AB, Lexa KW, Gardiner TE, LeRoux M, Vollmer W, Mougous JD. 2012. Structure of a peptidoglycan amidase effector targeted to Gram-negative bacteria by the type VI secretion system. Cell Rep 1:656-664. https://doi.org/10.1016/j.celrep.2012.05.016.

18. Lerner TR, Lovering AL, Bui NK, Uchida K, Aizawa S-I, Vollmer W, Sockett RE. 2012. Specialized peptidoglycan hydrolases sculpt the intra-bacterial niche of predatory Bdellovibrio and increase population fitness. PLoS Pathog 8:e1002524. https://doi.org/10.1371/journal.ppat.1002524.

19. Russell AB, Singh P, Brittnacher M, Bui NK, Hood RD, Carl MA, Agnello DM, Schwarz S, Goodlett DR, Vollmer W, Mougous JD. 2012. A widespread bacterial type $\mathrm{VI}$ secretion effector superfamily identified using a heuristic approach. Cell Host Microbe 11:538-549. https://doi.org/10.1016/j.chom .2012.04.007.

20. Russell AB, Hood RD, Bui NK, LeRoux M, Vollmer W, Mougous JD. 2011. Type VI secretion delivers bacteriolytic effectors to target cells. Nature 475:343-347. https://doi.org/10.1038/nature10244.

21. Kumar JK. 2008. Lysostaphin: an antistaphylococcal agent. Appl Microbiol Biotechnol 80:555-561. https://doi.org/10.1007/s00253-008-1579-y.

22. Claverys J-P, Håvarstein LS. 2007. Cannibalism and fratricide: mechanisms and raisons d'être. Nat Rev Microbiol 5:219-229. https://doi.org/10.1038/ nrmicro1613.

23. Schindler CA, Schuhardt VT. 1964. Lysostaphin: a new bacteriolytic agent for the Staphylococcus. Proc Natl Acad Sci U S A 51:414-421. https://doi .org/10.1073/pnas.51.3.414.

24. Anantharaman V, Aravind L. 2003. Evolutionary history, structural features and biochemical diversity of the NIpC/P60 superfamily of enzymes. Genome Biol 4:R11. https://doi.org/10.1186/gb-2003-4-2-r11.

25. Bannantine JP, Lingle CK, Adam PR, Ramyar KX, McWhorter WJ, Stabel JR, Picking WD, Geisbrecht BV. 2016. NIpC/P60 domain-containing proteins of Mycobacterium avium subspecies paratuberculosis that differentially bind and hydrolyze peptidoglycan. Protein Sci 25:840-851. https://doi .org/10.1002/pro.2884.

26. Xu Q, Mengin-Lecreulx D, Liu XW, Patin D, Farr CL, Grant JC, Chiu H-J, Jaroszewski L, Knuth MW, Godzik A, Lesley SA, Elsliger M-A, Deacon AM, Wilson IA. 2015. Insights into substrate specificity of NIpC/P60 cell wall hydrolases containing bacterial SH3 domains. mBio 6:e02327-14. https:// doi.org/10.1128/mBio.02327-14.

27. Xu Q, Sudek S, McMullan D, Miller MD, Geierstanger B, Jones DH, Krishna 
SS, Spraggon G, Bursalay B, Abdubek P, Acosta C, Ambing E, Astakhova T, Axelrod HL, Carlton D, Caruthers J, Chiu H-J, Clayton T, Deller MC, Duan L, Elias $Y$, Elsliger M-A, Feuerhelm J, Grzechnik SK, Hale J, Won Han G, Haugen J, Jaroszewski L, Jin KK, Klock HE, Knuth MW, Kozbial P, Kumar A, Marciano D, Morse AT, Nigoghossian E, Okach L, Oommachen S, Paulsen J, Reyes R, Rife CL, Trout CV, van den Bedem H, Weekes D, White A, Wolf G, Zubieta C, Hodgson KO, Wooley J, Deacon AM, et al. 2009. Structural basis of murein peptide specificity of a $\gamma$-D-glutamyl-L-diamino acid endopeptidase. Structure 17:303-313. https://doi.org/10.1016/j.str.2008.12 .008 .

28. Aramini JM, Rossi P, Huang YJ, Zhao L, Jiang M, Maglaqui M, Xiao R, Locke J, Nair R, Rost B, Acton TB, Inouye M, Montelione GT. 2008. Solution NMR structure of the NlpC/P60 domain of lipoprotein Spr from Escherichia coli: structural evidence for a novel cysteine peptidase catalytic triad. Biochemistry 47:9715-9717. https://doi.org/10.1021/bi8010779.

29. Pickersgill RW, Harris GW, Garman E. 1992. Structure of monoclinic papain at $1.60 \AA$ resolution. Acta Crystallogr B Struct Sci 48:59-67. https://doi .org/10.1107/S0108768191006572.

30. Broendum SS, Buckle AM, McGowan S. 2018. Catalytic diversity and cell wall binding repeats in the phage-encoded endolysins. Mol Microbiol 110:879-896. https://doi.org/10.1111/mmi.14134.

31. Kurochkina N, Guha U. 2013. SH3 domains: modules of protein-protein interactions. Biophys Rev 5:29-39. https://doi.org/10.1007/s12551-012 $-0081-z$.

32. Saksela K, Permi P. 2012. SH3 domain ligand binding: what's the consensus and where's the specificity? FEBS Lett 586:2609-2614. https://doi.org/ 10.1016/j.febslet.2012.04.042.

33. Buist G, Steen A, Kok J, Kuipers OP. 2008. LysM, a widely distributed protein motif for binding to (peptido)glycans. Mol Microbiol 68:838-847. https://doi.org/10.1111/j.1365-2958.2008.06211.x.

34. Shoseyov O, Shani Z, Levy I. 2006. Carbohydrate binding modules: biochemical properties and novel applications. Microbiol Mol Biol Rev 70:283-295. https://doi.org/10.1128/MMBR.00028-05.

35. Whisstock JC, Lesk AM. 1999. SH3 domains in prokaryotes. Trends Biochem Sci 24:132-133. https://doi.org/10.1016/s0968-0004(99)01366-3.

36. Barnes AC, dos Santos NM, Ellis AE. 2005. Update on bacterial vaccines: Photobacterium damselae subsp. piscicida, p 75-84. In Midtlyng PJ (ed), Progress in fish vaccinology, vol 121. Karger, Basel, Switzerland.

37. Romalde JL. 2002. Photobacterium damselae subsp. piscicida: an integrated view of a bacterial fish pathogen. Int Microbiol 5:3-9. https://doi .org/10.1007/s10123-002-0051-6.

38. Toranzo AE, Barja JL, Hetrick FM. 1982. Survival of Vibrio anguillarum and Pasteurella piscicida in estuarine and fresh waters. Bull Eur Assoc Fish Pathol 2:43-45.

39. Janssen WA, Surgalla MJ. 1968. Morphology, physiology, and serology of a Pasteurella species pathogenic for white perch (Roccus americanus). J Bacteriol 96:1606-1610. https://doi.org/10.1128/JB.96.5.1606-1610.1968.

40. Magariños B, Romalde JL, Barja JL, Toranzo AE. 1994. Evidence of a dormant but infective state of the fish pathogen Pasteurella piscicida in seawater and sediment. Appl Environ Microbiol 60:180-186. https://doi.org/ 10.1128/AEM.60.1.180-186.1994.

41. Mazzolini E, Fabris A, Ceschia G, Vismara D, Magni A, Amadei A, Passera A, Danielis L, Giorgetti G. 1998. Pathogenic variability of Pasteurella piscicida during in vitro cultivation as a preliminary study for vaccine production. J Appl Ichthyol 14:265-268. https://doi.org/10.1111/j.1439-0426.1998.tb00653.x.

42. Magariños B, Santos Y, Romalde JL, Rivas C, Barja JL, Toranzo AE. 1992. Pathogenic activities of live cells and extracellular products of the fish pathogen Pasteurella piscicida. J Gen Microbiol 138:2491-2498. https:// doi.org/10.1099/00221287-138-12-2491.

43. do Vale A, Costa-Ramos C, Silva A, Silva DS, Gartner F, dos Santos NM, Silva MT. 2007. Systemic macrophage and neutrophil destruction by secondary necrosis induced by a bacterial exotoxin in a Gram-negative septicaemia. Cell Microbiol 9:988-1003. https://doi.org/10.1111/j.1462-5822 .2006.00846.x.

44. do Vale A, Pereira C, Osorio CR, dos Santos NMS. 2017. The apoptogenic toxin AIP56 is secreted by the type II secretion system of Photobacterium damselae subsp. piscicida. Toxins 9:368. https://doi.org/10 $.3390 /$ toxins 9110368

45. do Vale A, Silva MT, dos Santos NMS, Nascimento DS, Reis-Rodrigues $P$, Costa-Ramos C, Ellis AE, Azevedo JE. 2005. AIP56, a novel plasmidencoded virulence factor of Photobacterium damselae subsp. piscicida with apoptogenic activity against sea bass macrophages and neutrophils. Mol Microbiol 58:1025-1038. https://doi.org/10.1111/j.1365-2958.2005 .04893.x.
46. Pereira $L M$, Pinto RD, Silva $D S$, Moreira $A R$, Beitzinger $C$, Oliveira $P$, Sampaio P, Benz R, Azevedo JE, Dos Santos NM, do Vale A. 2014. Intracellular trafficking of AIP56, an NF-kappaB cleaving toxin from Photobacterium damselae subsp. piscicida. Infect Immun 82:5270-5285. https://doi .org/10.1128/IAl.02623-14.

47. Silva DS, Pereira LMG, Moreira AR, Ferreira-da-Silva F, Brito RM, Faria TQ, Zornetta I, Montecucco C, Oliveira P, Azevedo JE, Pereira PJB, MacedoRibeiro S, do Vale A, dos Santos NMS. 2013. The apoptogenic toxin AIP56 is a metalloprotease A-B toxin that cleaves NF-Kb P65. PLoS Pathog 9: e1003128. https://doi.org/10.1371/journal.ppat.1003128.

48. Abushattal S, Vences A, Dos Santos NMS, do Vale A, Osorio CR. 2019. Draft genome sequences of Photobacterium damselae subsp. piscicida SNW8.1 and PP3, two fish-isolated strains containing a type III secretion system. Microbiol Resour Announc 8:e00426-19. https://doi.org/10.1128/ MRA.00426-19.

49. Aoki T, Teru Y, Morimoto N, Kono T, Sakai M, Takano T, Hawke JP, Fukuda Y, Takeyama H, Hikima Jl. 2017. Complete genome sequence of Photobacterium damselae subsp. piscicida strain OT-51443 isolated from yellowtail (Seriola quinqueradiata) in Japan. Genome Announc 5:e00404-17. https://doi.org/10.1128/genomeA.00404-17.

50. Balado M, Benzekri H, Labella AM, Claros MG, Manchado M, Borrego JJ, Osorio CR, Lemos ML. 2017. Genomic analysis of the marine fish pathogen Photobacterium damselae subsp. piscicida: insertion sequences proliferation is associated with chromosomal reorganisations and rampant gene decay. Infect Genet Evol 54:221-229. https://doi.org/10.1016/j .meegid.2017.07.007.

51. Drenth J, Kalk KH, Swen HM. 1976. Binding of chloromethyl ketone substrate analogs to crystalline papain. Biochemistry 15:3731-3738. https:// doi.org/10.1021/bi00662a014.

52. Xu G, Chance MR. 2005. Radiolytic modification of sulfur-containing amino acid residues in model peptides: fundamental studies for protein footprinting. Anal Chem 77:2437-2449. https://doi.org/10.1021/ac0484629.

53. Nivaskumar M, Francetic O. 2014. Type II secretion system: a magic beanstalk or a protein escalator. Biochim Biophys Acta 1843:1568-1577. https://doi.org/10.1016/j.bbamcr.2013.12.020.

54. Cianciotto NP, White RC. 2017. Expanding role of type II secretion in bacterial pathogenesis and beyond. Infect Immun 85:e0014-17. https://doi .org/10.1128/IAI.00014-17.

55. Abendroth J, Rice AE, McLuskey K, Bagdasarian M, Hol WG. 2004. The crystal structure of the periplasmic domain of the type II secretion system protein EpsM from Vibrio cholerae: the simplest version of the ferredoxin fold. J Mol Biol 338:585-596. https://doi.org/10.1016/j.jmb.2004.01.064.

56. Rico-Perez G, Pezza A, Pucciarelli MG, de Pedro MA, Soncini FC, Garcia-del Portillo F. 2016. A novel peptidoglycan D,L-endopeptidase induced by Salmonella inside eukaryotic cells contributes to virulence. Mol Microbiol 99:546-556. https://doi.org/10.1111/mmi.13248.

57. Núñez-Díaz JA, Fumanal M, do Vale A, Fernández-Díaz C, Moriñigo MÁ, Balebona MC. 2018. Transcription of IVIAT and virulence genes in Photobacterium damselae subsp. piscicida infecting Solea senegalensis. Microorganisms 6:67. https://doi.org/10.3390/microorganisms6030067.

58. do Vale A, Costa-Ramos C, Silva DS, Macedo PM, Fernandes R, Sampaio P, Dos Santos NM, Silva MT. 2007. Cytochemical and ultrastructural study of anoikis and secondary necrosis in enterocytes detached in vivo. Apoptosis 12:1069-1083. https://doi.org/10.1007/s10495-006-0040-x.

59. Phillips KE, Satchell KJF. 2017. Vibrio vulnificus: from oyster colonist to human pathogen. PLoS Pathog 13:e1006053. https://doi.org/10.1371/ journal.ppat.1006053.

60. Amaro C, Sanjuan E, Fouz B, Pajuelo D, Lee CT, Hor LI, Barrera R. 2015. The fish pathogen Vibrio vulnificus biotype 2: epidemiology, phylogeny, and virulence factors involved in warm-water vibriosis. Microbiol Spectr 3(3):VE-0005-2014. https://doi.org/10.1128/microbiolspec.VE-0005-2014.

61. Frans I, Michiels CW, Bossier P, Willems KA, Lievens B, Rediers H. 2011. Vibrio anguillarum as a fish pathogen: virulence factors, diagnosis and prevention. J Fish Dis 34:643-661. https://doi.org/10.1111/j.1365-2761 .2011.01279.x.

62. Terceti MS, Vences A, Matanza XM, Barca AV, Noia M, Lisboa J, dos Santos NMS, do Vale A, Osorio CR. 2019. The RstAB system impacts virulence, motility, cell morphology, penicillin tolerance and production of type II secretion system-dependent factors in the fish and human pathogen Photobacterium damselae subsp. damselae. Front Microbiol 10:897. https://doi.org/10.3389/fmicb.2019.00897.

63. Laemmli UK. 1970. Cleavage of structural proteins during the assembly of the head of bacteriophage T4. Nature 227:680-685. https://doi.org/10 .1038/227680a0. 
64. Coati A, Chavas LMG, Fontaine P, Foos N, Guimaraes B, Gourhant $P$, Legrand $P$, Itie JP, Fertey $P$, Shepard W, Isabet T, Sirigu S, Solari PL, Thiaudiere D, Thompson A. 2017. Status of the crystallography beamlines at synchrotron SOLEIL*. Eur Phys J Plus 132:174. https://doi.org/10.1140/ epjp/i2017-11403-3.

65. Kabsch W. 2010. XDS. Acta Crystallogr D Biol Crystallogr 66:125-132. https://doi.org/10.1107/S0907444909047337.

66. Winn MD, Ballard CC, Cowtan KD, Dodson EJ, Emsley P, Evans PR, Keegan RM, Krissinel EB, Leslie AG, McCoy A, McNicholas SJ, Murshudov GN, Pannu NS, Potterton EA, Powell HR, Read RJ, Vagin A, Wilson KS. 2011. Overview of the CCP4 suite and current developments. Acta Crystallogr D Biol Crystallogr 67:235-242. https://doi.org/10.1107/S0907444910045749.

67. McCoy AJ, Grosse-Kunstleve RW, Adams PD, Winn MD, Storoni LC, Read RJ. 2007. Phaser crystallographic software. J Appl Crystallogr 40:658-674. https://doi.org/10.1107/S0021889807021206.

68. Langer G, Cohen SX, Lamzin VS, Perrakis A. 2008. Automated macromolecular model building for X-ray crystallography using ARP/wARP version 7. Nat Protoc 3:1171-1179. https://doi.org/10.1038/nprot.2008.91.

69. Emsley P, Lohkamp B, Scott WG, Cowtan K. 2010. Features and development of Coot. Acta Crystallogr D Biol Crystallogr 66:486-501. https://doi .org/10.1107/S0907444910007493.

70. Adams PD, Afonine PV, Bunkoczi G, Chen VB, Davis IW, Echols N, Headd
JJ, Hung LW, Kapral GJ, Grosse-Kunstleve RW, McCoy AJ, Moriarty NW, Oeffner R, Read RJ, Richardson DC, Richardson JS, Terwilliger TC, Zwart PH. 2010. PHENIX: a comprehensive Python-based system for macromolecular structure solution. Acta Crystallogr D Biol Crystallogr 66:213-221. https://doi.org/10.1107/S0907444909052925.

71. Afonine PV, Grosse-Kunstleve RW, Echols N, Headd JJ, Moriarty NW, Mustyakimov M, Terwilliger TC, Urzhumtsev A, Zwart PH, Adams PD. 2012. Towards automated crystallographic structure refinement with phenix.refine. Acta Crystallogr D Biol Crystallogr 68:352-367. https://doi .org/10.1107/S0907444912001308.

72. Schrodinger, LLC. 2015. The PyMOL molecular graphics system, version 1.8 .

73. Meyer PA, Socias S, Key J, Ransey E, Tjon EC, Buschiazzo A, Lei M, Botka C, Withrow J, Neau D, Rajashankar K, Anderson KS, Baxter RH, Blacklow SC, Boggon TJ, Bonvin AMJJ, Borek D, Brett TJ, Caflisch A, Chang C-I, Chazin WJ, Corbett KD, Cosgrove MS, Crosson S, Dhe-Paganon S, Di Cera E, Drennan CL, Eck MJ, Eichman BF, Fan QR, Ferré-D'Amaré AR, Fromme JC, Garcia KC, Gaudet R, Gong P, Harrison SC, Heldwein EE, Jia Z, Keenan RJ, Kruse AC, Kvansakul M, McLellan JS, Modis Y, Nam Y, Otwinowski Z, Pai EF, Pereira PJB, Petosa C, Raman CS, Rapoport TA, et al. 2016. Data publication with the structural biology data grid supports live analysis. Nat Commun 7:10882. https://doi.org/10.1038/ncomms10882. 